Permission to place a copy of this work on this server has been provided by the American Meteorological Society. The AMS does not guarantee that the copy provided here is an accurate copy of the published work. 


\title{
Rainfall Types in the West African Sudanian Zone during the Summer Monsoon 2002
}

\author{
A. H. FINK \\ Institute of Geophysics and Meteorology, University of Cologne, Cologne, Germany \\ D. G. VINCENT \\ Department of Earth and Atmospheric Sciences, Purdue University, West Lafayette, Indiana \\ V. ERMERT \\ Institute of Geophysics and Meteorology, University of Cologne, Cologne, Germany
}

(Manuscript received 20 April 2005, in final form 1 November 2005)

\begin{abstract}
Enhanced surface and upper-air observations from the field campaign of the Integrated Approach to the Efficient Management of Scarce Water Resources in West Africa (IMPETUS) project are used to partition rainfall amounts over the West African Sudanian zone during the 2002 summer monsoon season into several characteristic types and subtypes of precipitating systems. The most prominent rainfall subtype was fast-moving, long-lived, and extensive cloud clusters that often developed far upstream over the central Nigerian highlands in the afternoon hours and arrived at the Upper Ouémé Valley (UOV) after midnight. These organized convective systems (advective OCSs, subtype Ia) accounted for 50\% of the total rain amount in the UOV catchment in Benin. Subtypes Ia and IIa (i.e., locally developing OCSs) were found to pass by or organize when a highly sheared environment with deep and dry midtropospheric layers was present over the UOV. These systems were most frequent outside the peak of the monsoon season. The second major type of organized convection, termed mesoscale convective systems (subtypes Ib, IIb, and IIIb) in the present study, contributed $26 \%$ to the annual UOV precipitation. They occurred in a lesssheared and moister tropospheric environment mainly around the height of the rainy season. A third distinct class of rainfall events occurred during an unusual synoptic situation in which a cyclonic vortex to the north of the UOV led to deep westerly flow. During these periods, the African easterly jet was lacking. The so-called vortex-type rainfalls (subtypes IIIa, IIIb, and IIIc) contributed about $9 \%$ to the annual rainfall totals.
\end{abstract}

\section{Introduction}

Tropical West Africa is known for its variable climate, where trends and decadal variability in rainfall have been far larger in recent years than at other places on earth. Associated changes in the latent heat release over the West African monsoon region will impact the large-scale tropical circulation. Moreover, decadal wet and dry periods over the western Sahel are known to be strongly related to above- and below-normal activity of intense Atlantic hurricanes, respectively, during the 1949-90 period (Landsea and Gray 1992). In addition

Corresponding author address: Andreas H. Fink, Institute of Geophysics and Meteorology, University of Cologne, Kerpener Strasse 13, D-50923 Köln, Germany.

E-mail: fink@meteo.uni-koeln.de to these impacts on the large-scale climate, rainfall distributions over West Africa have been studied extensively because of their importance to the economy, agriculture, and freshwater resources of the region. Since it is the anomalous statistic of the individual rainfallproducing weather systems in the region that accounts for the variability in the climatological precipitation amount (e.g., Le Barbé and Lebel 1997; Shinoda et al. 1999; Le Barbé et al. 2002), it is important to improve our limited understanding of the basic mechanism of their genesis, growth, propagation, and decay. Using unprecedented surface and upper-air data, collected within the framework of the Integrated Approach to the Efficient Management of Scarce Water Resources in West Africa (IMPETUS) and Analyse Multidisciplinaire de la Mousson Africaine/Couplage de l'Atmosphère Tropicale et du Cycle Hydrologique (AMMA/ 
$\mathrm{CATCH})$ projects in the Sudanian zone $\left(9^{\circ}-12^{\circ} \mathrm{N}\right)$ of eastern West Africa $\left(0^{\circ}-10^{\circ} \mathrm{E}\right)$ during the rainy season of 2002, the present study aims at improving the insights into West African rainfall types and their characteristic kinematic and thermodynamic environments.

Several types of precipitation systems have been found to cause rainfall over West Africa during the summer monsoon season. These comprise, but are not restricted to, organized mesoscale convective systems (MCSs), monsoon rains, and unorganized local thunderstorms or showers. Among the MCS category, various authors have discussed squall- or disturbance-line systems (SLs; e.g., Hamilton and Archbold 1945; Eldridge 1957; Aspliden et al. 1976; Chong et al. 1987; Chong and Hauser 1989; Roux 1988; Peters et al. 1989; Rowell and Milford 1993), organized convective systems (OCSs; Mathon et al. 2002b, hereafter MA02), and mesoscale convective complexes (MCCs; MA02; Laing et al. 1999).

The Global Atmospheric Research Program (GARP) Atlantic Tropical Experiment (GATE), held over tropical western Africa and the eastern Atlantic region, brought about a considerable advancement in our understanding of the statistical properties and mesoscale structure of SLs, as well as their interaction with the larger-scale flow [see reviews of Houze and Betts (1981) and Greenfield and Fein (1979)]. While most convective case studies investigated events over the GATE ship array, Zipser (1977) and Fortune (1980) described SL cases over West Africa. In the latter study, it is shown for a West African SL system that five SLs, lasting an average of 6-12 h, were embedded in a longer-lived, westward-propagating parent cloud cluster that lasted more than $48 \mathrm{~h}$. With respect to the land-based SLs, the Convection Profonde Tropicale 1981 (COPT 81) field experiment in Ivory Coast (Sommeria and Testud 1984) provided further insight into the mesoscale processes that maintain West African SLs through the use of dual-Doppler radar data. In addition, other studies found that the low-level wind shear and the midlevel dryness are related to the occurrence and degree of organization of West African SLs (e.g., Barnes and Sieckman 1984; Peters and Tetzlaff 1988; Peters et al. 1989; Hodges and Thorncroft 1997; Thorncroft et al. 2003).

Squall or disturbance lines have been identified using solely surface station observations (Hamilton and Archbold 1945; Eldridge 1957; Acheampong 1982; Omotosho 1984, 1985), infrared (IR) (Aspliden et al. 1976; Desbois et al. 1988; Rowell and Milford 1993; Mathon and Laurent 2001; MA02), or microwave satellite imagery (Fink and Reiner 2003, hereafter FR03).
Using $10 \mathrm{yr}$ of rain gauge and Meteosat IR satellite data, MA02 examined rainfall amounts by MCSs, MCCs, and OCSs in the Sahel (southwest Niger) and found that $90 \%$ of the estimated rainfall was produced by OCSs that appear to have characteristics similar to those of SLs. This is consistent with the findings of Dhonneur (1981) that $80 \%$ of the annual precipitation in the semiarid Sahel is due to SL activity. This fraction reduces to about $50 \%$ in the semihumid Sudanian climate zone (Eldridge 1957; Omotosho 1985) and further decreases to values between $16 \%$ and $32 \%$ at the Guinean coast (Acheampong 1982; Omotosho 1985). At these more southerly latitudes, the two other season rainfall types seem to become increasingly important. In the Sudanian zone of Nigeria, Omotosho (1985) noted a $40 \%$ contribution of local thunderstorms to the annual rainfall total. Along parts of the Ghanaian Gold Coast, $50 \%$ of the annual rainfall is related to monsoonal rains (Acheampong 1982). While previous studies suggest that monsoon rains are related to largerscale dynamic forcing mechanisms, there appears to be no commonly accepted definition of this rainfall type (cf. Eldridge 1957; Kamara 1986; Buckle 1996). In this study, we consider "monsoonal rains" being prolonged periods of steady or intermittent, light to moderate rains from rainstorms with a low electrical activity and developing in a low-shear environment near the surface.

Westward-propagating, low-level African easterly waves (AEWs) are the dominant synoptic-scale features of the West African monsoon and the tropical Atlantic during boreal summer. Carlson (1969a,b) published one of the first case studies to document their propagation over West Africa and progress over the Atlantic, as well as their role as precursors for Atlantic tropical cyclogenesis. The interaction of AEWs with rainfall or SL life cycles has been discussed in various papers (e.g., Reed et al. 1977; Payne and McGarry 1977; Duvel 1990; Rowell and Milford 1993; Diedhiou et al. 1999; FR03; Fink et al. 2004). FR03 provide a good summary of AEW-SL relationships. Over all of West Africa, the wave phase that accounted for the highest fraction of SL generation (almost 50\%) were just west (i.e., ahead) of the trough, but a secondary peak occurred in the Sahel east (i.e., behind) of the trough in the wave phase that is associated with maximum lowlevel southerly wind anomalies. FR03 concluded that AEWs played a larger role in triggering SLs west of the Greenwich meridian (GM) and in the Sahel.

In the present study, the types of rainfall and the role of AEWs are examined for the Upper Ouémé Valley (UOV) during the March-October 2002 rainfall period. 
The UOV is located just east of the GM in the semihumid Sudanian zone of central Benin (see maps in Fig. 1) and is selected because a large number of rain gauges and a temporary upper-air radiosonde station were operated during the rainy season of 2002 (Fig. 1). Using this enhanced observational dataset, the objectives of the present study are to

1) define a set of distinct UOV rainfall types and subtypes and compute their rainfall statistics;

2) diagnose changes in composite vertical atmospheric profiles at Parakou, Benin (cf. Fig. 1b), that are associated with the passage of the more frequent subtypes; and

3) specify the evolution of the AEW and OCS/MCS phase relationship as the systems propagate westward across the UOV.

The data sources and methods are described in sections 2 and 3. Results are discussed in section 4, and summary and concluding remarks are provided in section 5 .

\section{Data sources}

The cloud systems were identified and tracked (cf. section 3a) using rectified, inverted, and unenhanced IR $(10.8 \mu \mathrm{m})$ channel Meteosat-7 satellite images in half-hourly resolution provided by the German Weather Service (DWD). The images covered the area between $0^{\circ}$ and $40^{\circ} \mathrm{N}$, and $28.2^{\circ} \mathrm{W}$ and $28.2^{\circ} \mathrm{E}$ with a horizontal resolution of $5 \times 5 \mathrm{~km}^{2}$ at the subsatellite point. Precipitation events in the UOV region were examined with the help of 49 recording rain gauges distributed unevenly over the catchment area of about $20000 \mathrm{~km}^{2}$ (Fig. 1b). The rainfall intensities were converted into 6-min intervals after a quality control check, and then averaged over all operating stations.

Since the beginning of the 1980s, no upper-air station has been operational during an entire rainy season in the West African Sudanian zone. Thus, the in situ profiles of temperature, humidity, pressure, and wind with a vertical grid resolution of $10 \mathrm{~m}$ that were collected from the IMPETUS radiosonde campaign at Parakou $\left(9^{\circ} 21^{\prime} \mathrm{N}\right.$; $2^{\circ} 37^{\prime} \mathrm{E}$; see map in Fig. 1a) represent a unique dataset to study the vertical structure of the atmosphere before and after major rainfall events in this more humid climate zone of West Africa. Twice daily, at 0000 and 1200 UTC, Vaisala RS80 GPS wind sondes with an A-Humicap were released. The data were transmitted in real time to the European Centre for Medium-Range Weather Forecasts (ECMWF) and the DWD, and were assimilated into their operational analyses. Because of an erroneous configuration of the ground station, winds transmitted in real time were flawed during parts of the ascents until 6 August 2002. The erroneous winds were corrected by postprocessing the raw data.

The six-hourly (0000, 0600, 1200, and 1800 UTC) operational ECMWF pressure-level analyses on a $1^{\circ} \times 1^{\circ}$ latitude-longitude grid were used to investigate the relationship between AEWs and cloud systems. By inspecting the analysis increments used to correct the four-dimensional variational data assimilation (4DVAR) forecast for each sounding at Parakou, it was concluded that erroneous real-time radiosonde winds before $6 \mathrm{Au}$ gust 2002 were mostly rejected by the analysis scheme, but occasionally flawed the wind analysis.

\section{Definitions and methods}

\section{a. Cloud tracking}

In the present study, cloud clusters are delineated and classified semiautomatically using IR brightness temperatures of 233 and $213 \mathrm{~K}$, respectively (cf. Fig. 2a). These thresholds are widely used to identify deep convection often associated with substantial rainfall amounts (e.g., Duvel 1989; Arnaud et al. 1992; Laing et al. 1999; Mathon and Laurent 2001; MA02; Taylor et al. 2005). The origin of cloud clusters that caused rainfall in the UOV region were identified by tracking them visually backward in IR satellite loops. The exact times and locations of cloud cluster initiation were determined when at least one pixel shows, for the first time, temperatures that are lower or equal to $233 \mathrm{~K}$ (Fig. 2b). Automated tracking is utilized after initiation if the cloud areas extensively overlap in subsequent halfhourly images. To accomplish this, the "center of gravity" of the $233-\mathrm{K}$ cloud envelope is calculated and the $233-\mathrm{K}$ cloud system of the subsequent image is assigned to the old cluster if the old center of gravity is located within the new cloud system. If the automated cloud tracking stops, the cloud system may have dissipated. From a mandatory visual inspection, it was then subjectively decided if the system really dispersed or if the tracking has to be manually restarted. Further subjectivity was introduced into the tracking procedure in cases when clusters split or merged, or if they dissipated and regenerated immediately afterward (cf. Arnaud et al. 1992). If more than one cloud system moved over the UOV during a continuous rainfall event, they were all tracked.

An example of the result of the tracking algorithm is shown in Fig. 2b for a long-lived cloud system affecting the UOV in the evening hours of 3 September 2002. The principal propagation direction, west-southwest, is typical of West African cloud clusters (FR03). The time of initiation of the cloud system just west of Lake Chad 
(a)

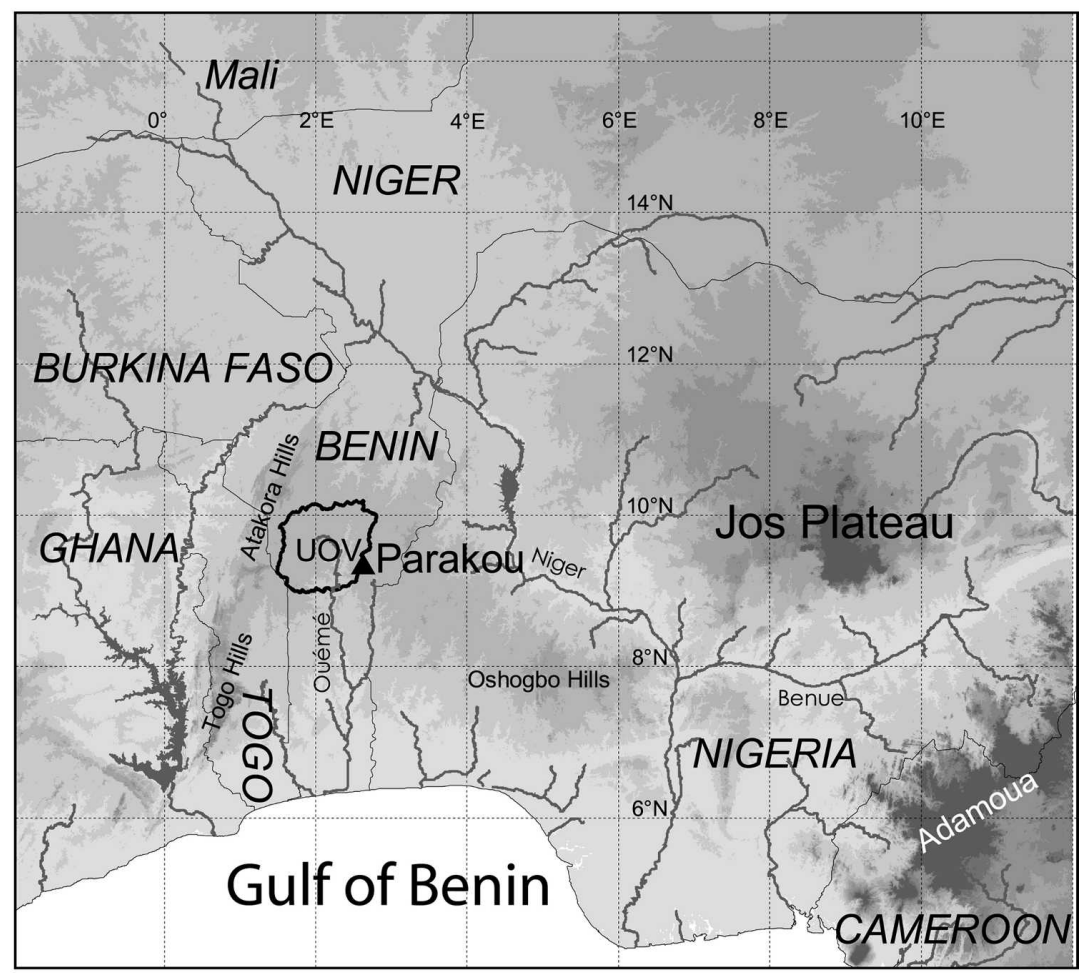

$0 \quad 150 \quad 300 \quad 450 \quad 600 \quad 750 \quad 900 \quad 1050$

(b)
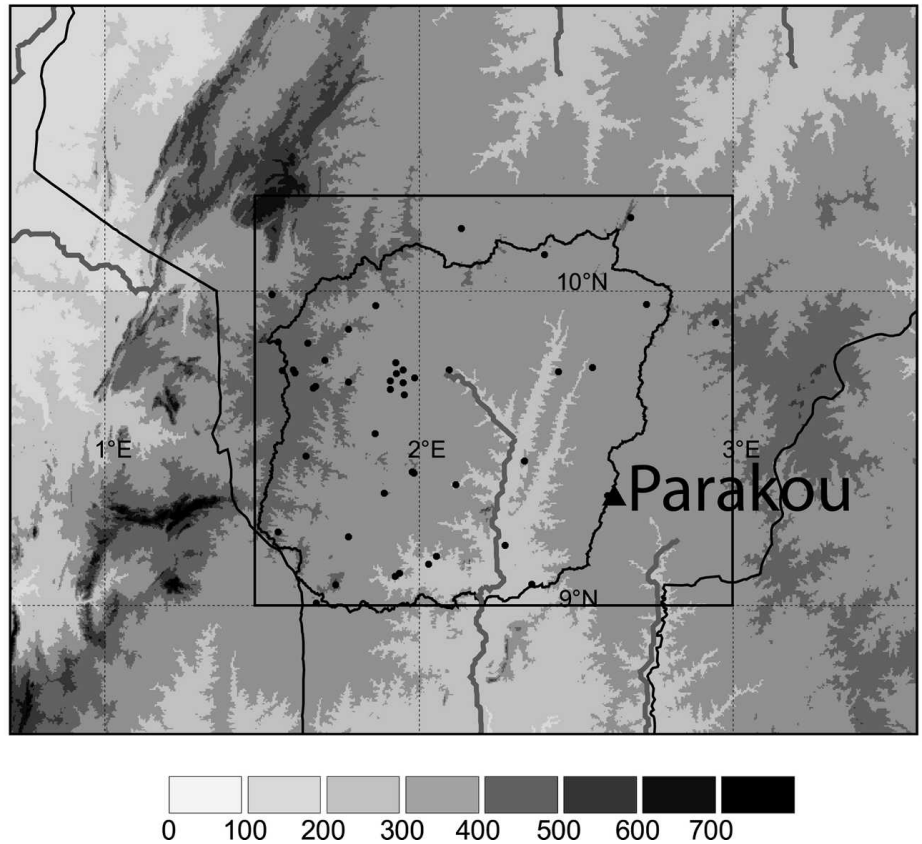

FIG. 1. (a) Map of Benin and vicinity showing orography, including the names of major highlands, political borders, major rivers, and the UOV catchment boundaries. At Parakou, located at the eastern fringe of the UOV, radiosondes were launched between May and mid-October 2002. (b) Close-up view of the UOV. The black dots denote the locations of the 49 recording rain gauges in the UOV region. The UOV box $\left(9^{\circ}-10.3^{\circ} \mathrm{N}, 1.5^{\circ}-3^{\circ} \mathrm{E}\right)$ is indicated by the black rectangle. It encompasses all rain gauges and is used in the satellite study. 

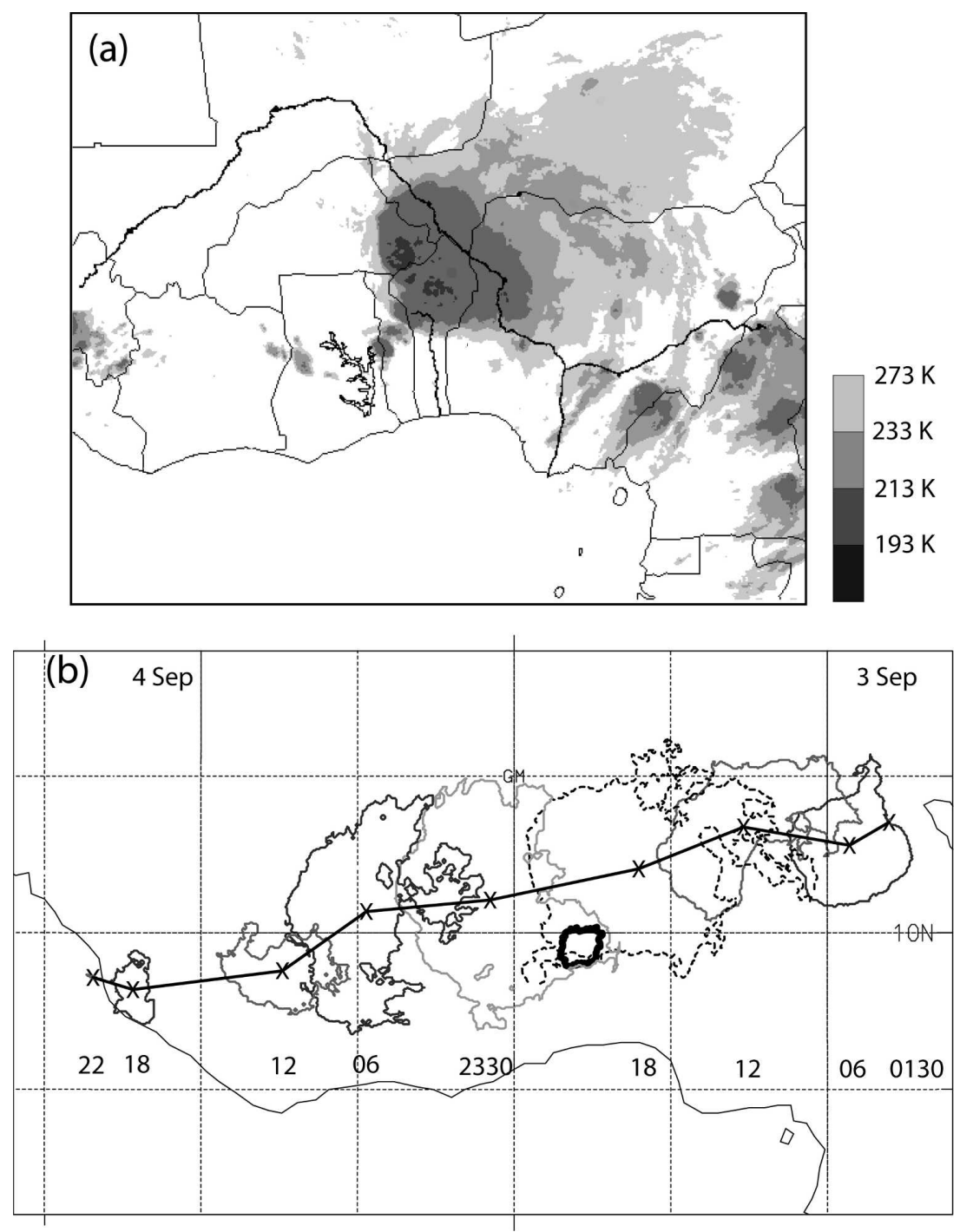

FIG. 2. Meteosat infrared image at 1800 UTC 3 Sep 2002. Shading indicates brightness temperatures. (b) Six-hourly cloud envelopes between the initiation of the system at 0130 UTC 3 Sep and its lysis at 2200 UTC 4 Sep 2002. The cloud envelopes encompass areas with brightness temperatures lower than $233 \mathrm{~K}$. The dashed envelope denotes the cloud system shown in (a). The solid black line depicts the track of the cloud system. It is obtained by connecting the "centers of gravity" of the cloud system, as defined by the 233-K envelope, at 6-h time increments by a straight line. The area delineated by the boldface solid line is the UOV catchment.

on 0130 UTC 3 September is unusual (cf. Berry and Thorncroft 2005), but the system increased in areal extent and intensity during the following daylight hours. Figure 2a shows the extent of the cloud system in different IR temperatures as it reached the UOV at 1800 UTC 3 September 2002. Note from Fig. 2a that the coldest IR temperatures occur in the leading western part of the system.

The cloud propagation speed is another indicator of its degree of organization (Roux et al. 1984; MA02).
Cloud clusters are often characterized by warmer and nearly stationary clouds during their initiation and dissipation phases. Thus, the centers of gravity of the colder 213-K cloud envelope were used to determine the average propagation velocity. The translation speed was calculated by dividing the distance of the $213-\mathrm{K}$ centers at the initiation and lysis point by the $213-\mathrm{K}$ lifetime. The cloud tracking method is described in detail in Ermert (2004) and is similar to the method introduced in MA02. 
TABLE 1. Criteria used to define the types and subtypes of precipitating systems, where $P(u=0)=$ pressure level of zonal wind change from westerly to easterly, $t_{\mathrm{UOV}}=$ time between the initiation and arrival in the UOV box of a $233-\mathrm{K}$ cloud system, $F_{233 \mathrm{~K}}=$ area encompassed by the $233-\mathrm{K}$ brightness temperature, $F_{213 \mathrm{~K}}=$ area encompassed by the $213-\mathrm{K}$ brightness temperature, and $v_{213 \mathrm{~K}}=$ propagation speed of the cloud system based on 213-K brightness temperature.

\begin{tabular}{|c|c|c|c|c|c|c|c|}
\hline Type & Subtype & Name & $\begin{array}{c}P(u=0) \\
(\mathrm{hPa})\end{array}$ & $\begin{array}{c}t_{\mathrm{UOV}} \\
(\mathrm{h})\end{array}$ & $\begin{array}{c}F_{233 \mathrm{~K}} \\
\left(10^{3} \mathrm{~km}^{2}\right)\end{array}$ & $\begin{array}{c}F_{213 \mathrm{~K}} \\
\left(10^{3} \mathrm{~km}^{2}\right)\end{array}$ & $\begin{array}{c}v_{213 \mathrm{~K}} \\
\left(\mathrm{~m} \mathrm{~s}^{-1}\right)\end{array}$ \\
\hline \multirow[t]{2}{*}{ I } & $\mathrm{a}$ & Advective OCS & \multirow[t]{2}{*}{$\geq 700$} & \multirow[t]{2}{*}{$>2$} & \multirow[t]{2}{*}{$>5$} & $>5$ for $3 \mathrm{~h}$ & $\geq 10$ \\
\hline & $\mathrm{b}$ & Advective MCS & & & & - & - \\
\hline \multirow[t]{3}{*}{ II } & $\mathrm{a}$ & Local OCS & & \multirow[t]{3}{*}{$\leq 2$} & & $>5$ for $3 \mathrm{~h}$ & $\geq 10$ \\
\hline & $\mathrm{b}$ & Local MCS & & & & - & - \\
\hline & $\mathrm{c}$ & Local instability storm & & & $\leq 5$ & - & - \\
\hline \multirow[t]{3}{*}{ III } & $\mathrm{a}$ & Vortex OCS & \multirow[t]{3}{*}{$<700$} & \multirow[t]{3}{*}{ - } & $>5$ & \multirow{3}{*}{$\begin{array}{c}>5 \text { for } 3 \mathrm{~h} \\
-\end{array}$} & \multirow{3}{*}{$\begin{array}{l}\geq 10 \\
-\end{array}$} \\
\hline & $\mathrm{b}$ & Vortex MCS & & & & & \\
\hline & $\mathrm{c}$ & Vortex instability storm & & & $\leq 5$ & & \\
\hline
\end{tabular}

\section{b. Definitions of UOV rainfall events and types}

In the present paper, the beginning of a UOVnetwork precipitation event is defined when rain is first reported at any of the 49 rain gauges. The event terminates when all rain gauges do not record any rainfall for a period longer than $30 \mathrm{~min}$. Using these definitions, the rainy season of 2002 was characterized by 637 precipitation events within the UOV rain gauge network. To reduce the sample size and to focus on the more intense and widespread rains, a so-called UOV rainfall event was defined if at least $30 \%$ of the operating rain gauges (ground area criterion) report equal or more than $1 \mathrm{~mm}$ of rain (ground intensity criterion). Its cessation was determined in the same way as mentioned above for the UOV-network precipitation events (ground time criterion). These three criteria are identical to those used in MA02 to define EPSAT Niger (EN) rain events from a network of 30 rain gauges in a $160 \times 110 \mathrm{~km}^{2}$ area around Niamey (Niger). Applying the above-mentioned criteria, 95 UOV rainfall events were selected during which a network-mean accumulation of $1022 \mathrm{~mm}$ occurred. This amounts to $90 \%$ of the accumulated March-October 2002 rainfall of $1132 \mathrm{~mm}$.

Starting from the representative sample of $95 \mathrm{UOV}$ rainfall events, three major UOV rainfall types are introduced based on the genesis location of the associated cloud cluster and the regional vertical wind profile:

1) advective cloud systems (type I), that is, any part of the 233-K cloud envelope that did not reach the UOV box within $2 \mathrm{~h}$ after its initiation;

2) local precipitation (type II); that is, cloud systems that caused UOV rain events originated inside the UOV box or the $233-\mathrm{K}$ cloud complex entered it within less than $2 \mathrm{~h}$ after its initiation (Note that local precipitation also emerged through local instability storms that were not tracked.); and

3) vortex-related rainfall events (type III), that is, a quasi-stationary, low- to midtropospheric vortex that was present north of the UOV and deep westerlies (i.e., a positive zonal wind component predominated from the surface up to heights above $700 \mathrm{hPa}$ ) occurred over Parakou for at least $12 \mathrm{~h}$, or more.

The three major types were subdivided using specific characteristics of the tracked cloud systems. MA02 defined so-called organized convective systems as rapid moving, long-lived, and organized cloud clusters meeting the following criteria:

1) the cluster is an MCS; that is, the area of IR temperatures equal to, or lower than, $233 \mathrm{~K}$ exceeds $5000 \mathrm{~km}^{2}$ during the entire lifetime of an OCS;

2) the cluster must have a propagation speed of at least $10 \mathrm{~m} \mathrm{~s}^{-1}$ (cf. section 3a); and

$3)$ the area with IR temperatures equal to or lower than $213 \mathrm{~K}$ within the contiguous area of $233-\mathrm{K}$ values must exceed $5000 \mathrm{~km}^{2}$ over at least three subsequent hours.

Because of criterion 3, and especially 2, it is reasonable to assume that many OCSs are identical to classical West African SL systems (MA02). All clusters that satisfy criterion 1 , but fulfill none or only one of criteria 2 and 3 are henceforth called MCSs. UOV rainfall events that were associated with clouds over the UOV box (Fig. 1b) that do not meet criterion 1 are termed "instability storms," as these are smaller-scale events.

The two types of cloud systems, OCSs and MCSs, as well as local instability storms are typical of the wet season over the West African subcontinent. OCSs, MCSs, and instability storms are now used to define subtypes a, b, and c, respectively, of types I, II, and III. A summary of the above-noted criteria to define the eight subtypes is given in Table 1. As can be seen from Table 2, 106 subtype events, consisting of tracked cloud clusters and instability showers, were identified from 
TABLE 2. Statistics of rainfall types and subtypes based on 95 major UOV rainfall events. The term "all systems" comprises all tracked cloud systems that were assigned to a subtype. Note that out of the 95 UOV rainfall events, 6 were caused by cloud systems of different types. Row 2 gives the statistics of UOV rainfall events caused by one or more cloud system of the same type. Similarly, row 3 provides the number of UOV rainfall events that are caused by one or more cloud systems of the same subtype.

\begin{tabular}{lcccccccrrr}
\hline \hline \multicolumn{1}{c}{ Attribute } & Ia & Ib & IIa & IIb & IIc & IIIa & IIIb & IIIc & $\Sigma$ & Mix \\
\hline All systems & 52 & & 9 & 8 & 21 & 1 & 1 & 12 & 2 & 106 \\
Same type events & & 51 & & & 25 & & & 13 & & 89 \\
Same subtype events & 42 & 8 & 6 & 18 & 1 & 1 & 10 & 2 & 88 & 7 \\
\hline
\end{tabular}

the $95 \mathrm{UOV}$ rainfall events. This larger number is due to single UOV rainfall events for which more than one cloud subtype contributed to the precipitation. The low figure of three local instability storms is a result of their localized and weak nature.

The evolution of the weather conditions leading to an absence of the African easterly jet (AEJ) and, thereby, to a low-shear environment in the lower troposphere during type III events has not been documented in earlier studies. Thus, two examples will be described below. In 2002, a total of four episodes with a westerly component of the wind up to a height of $8 \mathrm{~km}$ were observed over the UOV region, three of which occurred during the well-established summer monsoon circulation in late July/early August. The first of these three periods (example 1) was observed between 0000 UTC 26 July and 1200 UTC 29 July 2002 (Fig. 3a) and is noteworthy because the deep westerly winds at Parakou were barely captured in the ECMWF analysis (Fig. $3 c$ ), likely due to flawed real-time winds (cf. section 2). Only at 1200 UTC 26 July 2002, between 5 and 6 km, were westerlies depicted. The $500-\mathrm{hPa}$ streamline analysis on this date shows a quasi-stationary vortex just northeast of the UOV (Fig. 3e). It caused a westerly wind component to its south and southwest. It must be emphasized here that this cyclonic center has not been identified as a southerly AEW vortex using the AEW tracking technique described in FR03. Such an AEW vortex was located farther east at $10^{\circ} \mathrm{E}$ (see "S" in Fig. 3e).

The fourth period (example 2) between 30 September and 4 October 2002 differed from the others. Here, the deep westerlies (Fig. 3b) were initially related to the intrusion of a mid- to upper-level extratropical trough deep into the Tropics (Fig. 3f). The excursions of upper-level subtropical troughs into the West African Tropics are a typical feature of the transition period between the fully established summertime West African monsoon and the Northern Hemisphere wintertime circulation (Knippertz et al. 2003; Fink and Knippertz 2003). The evolution of this weather pattern was much better captured by the ECMWF analysis (Fig. 3d). The midtropospheric cutoff low at $21^{\circ} \mathrm{N}, 1^{\circ} \mathrm{W}$ that is dis- cernible in the $500-\mathrm{hPa}$ streamline analysis on 1200 UTC 1 October 2002 in Fig. 3f led to an anomalously westerly flow between the Guinean coast and $15^{\circ} \mathrm{N}$ at longitudes from $2.5^{\circ} \mathrm{E}$ to $7.5^{\circ} \mathrm{W}$ on that day. As a result an initially westward-propagating southerly AEW vortex (see "S" in Fig. 3f) was steered to the northwest causing a sustained westerly wind period at Parakou on its southern flank.

\section{Results and discussion}

It is appropriate to begin with a brief statement concerning the overall rainfall patterns over West Africa in 2002. On the continental scale and based on a combined satellite- and rain gauge-derived precipitation analysis, West Africa experienced a drier-than-normal year to the west, including the northwestern parts, of Benin (Waple and Lawrimore 2003). In contrast, the entire Gulf of Guinea and central Nigeria, including the Jos Plateau, was wetter than normal. A more regional perspective based on surface data from Benin, Nigeria, and Togo yields the following salient features of the 2002 rainy season: 1) rains in the UOV started early on 7 March 2002 and ended unusually late on 4 November 2002; 2) the UOV network-mean annual total of $1132 \mathrm{~mm}$ is very close to the 1960-91 mean value of $1110 \mathrm{~mm}$ based on six stations in the UOV region with long-term records; 3 ) the first part of the rainy season in the UOV between January and July was somewhat drier (about 10\%) than normal, whereas the August-October period experienced above-average totals on the order of $20 \%$; and 4) monthly gauge data from 12 Nigerian synoptic stations indicate aboveaverage rainfall over the central Nigerian highlands.

\section{a. General characteristics of rainfall systems}

Characteristics for each subtype of convective system, except for instability showers (i.e., subtypes IIc and IIIc), are shown in Fig. 4. Notice that "a" and "b" subtypes (i.e., OCSs and MCSs) are distinguishable in Fig. 4 by the dark and light gray shading of the bars, respectively. It is seen that the areas occupied by the 
00 UTC 23 July - 12 UTC 03 August

(a)

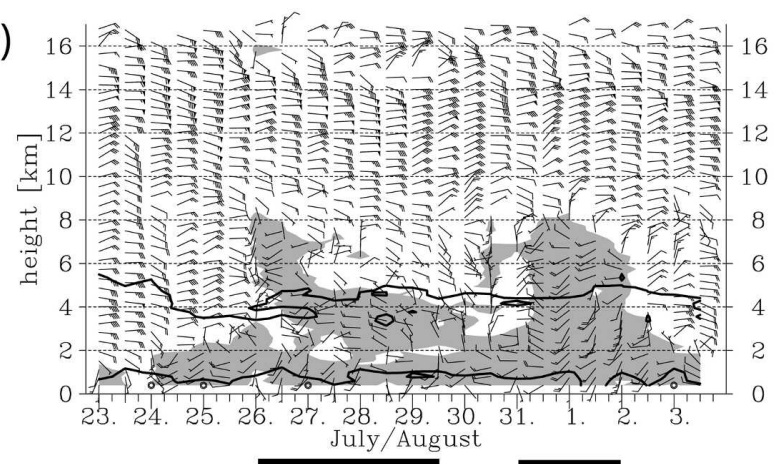

(c)

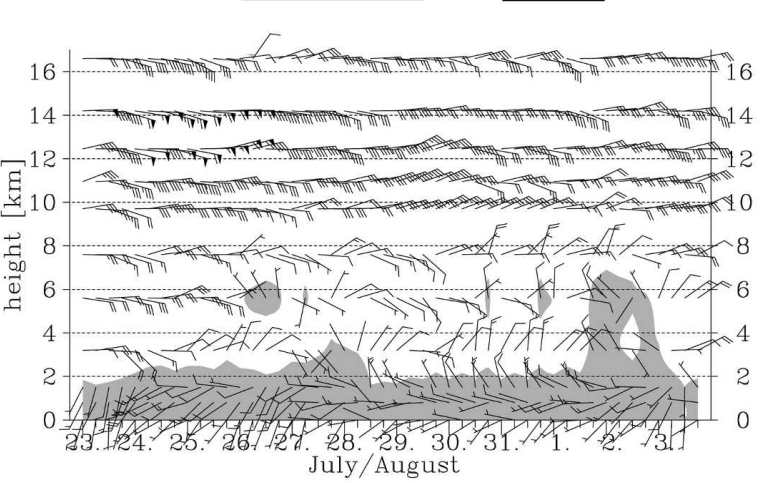

12 UTC 26 July

(e)

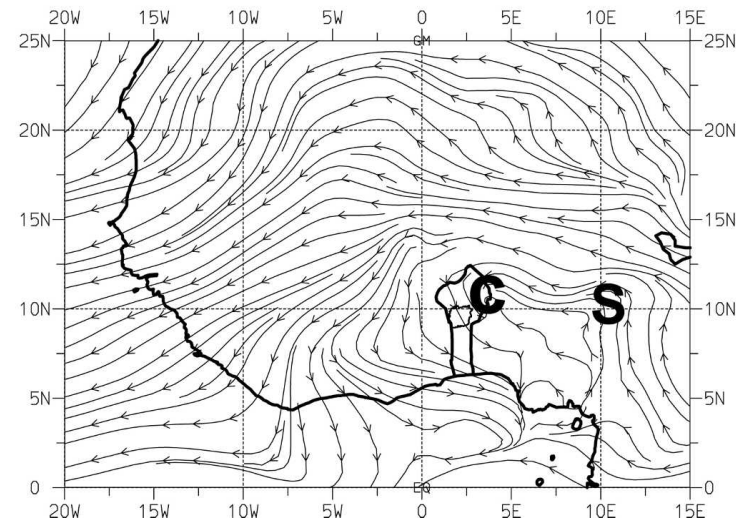

00 UTC 26 September - 18 UTC 07 October

(b)

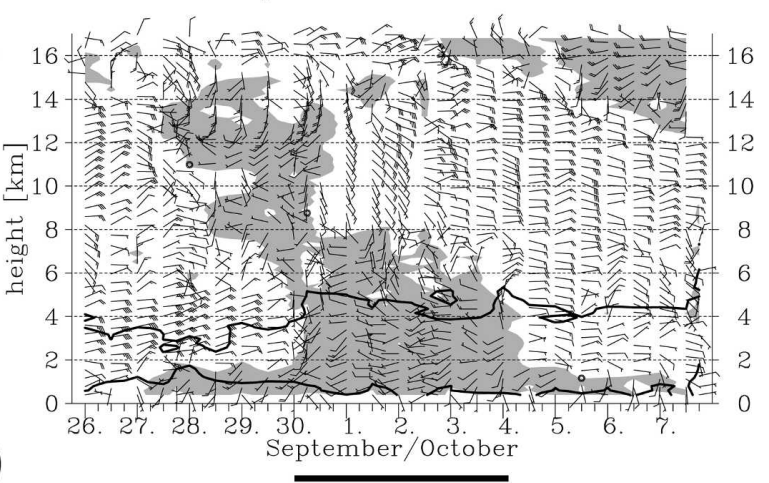

(d)

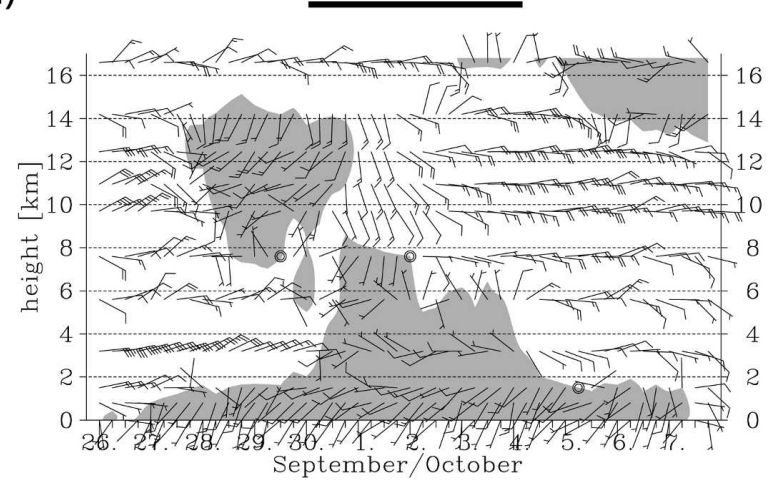

12 UTC 01 October

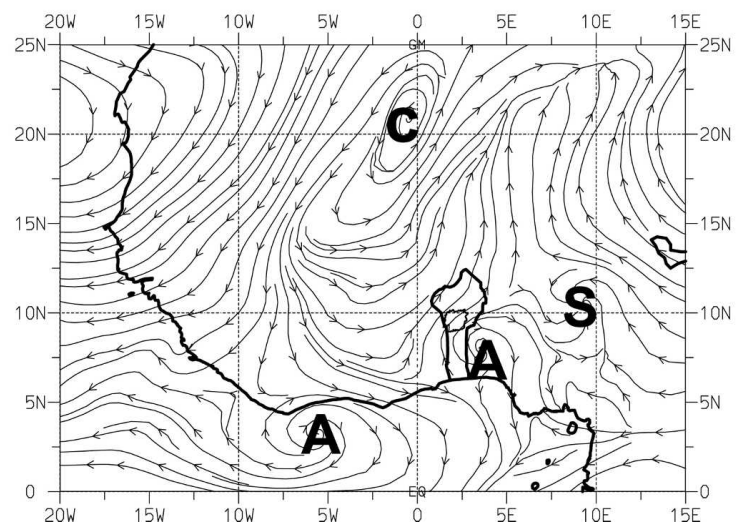

FIG. 3. (a) Time-height cross section of the 12-hourly radiosonde winds at Parakou, Benin, from 0000 UTC 23 Jul to 1200 UTC 3 Aug 2002. The vertical resolution is $400 \mathrm{~m}$. Shaded areas indicate a westerly component. The thick line underneath the panel denotes the period with the deep westerly flow. Also shown are specific humidity contours (thick lines) of 5 and $15 \mathrm{~g} \mathrm{~kg}^{-1}$, respectively. (b) As in (a) but for the period from 0000 UTC 26 Sep to 1800 UTC 7 Oct 2002. Soundings in addition to the 0000 and 1200 UTC launches are also displayed. (c) As in (a), but for ECMWF winds at the standard pressure levels and without humidity contours. (d) As in (c), but for the period displayed in (b). (e) Streamlines at $500 \mathrm{hPa}$ for $1200 \mathrm{UTC} 26 \mathrm{Jul}$ 2002. (f) As in (c), but for 1200 UTC 1 Oct 2002. In (e) and (f), some relevant cyclones ("C"), anticyclones ("A"), and southerly AEW vortices ("S") are labeled.

advective type I systems are much greater than the areas that encompass types II and III (Fig. 4a). Among the advective systems, the OCSs (subtype Ia) show the largest areal coverage of contiguous $233-\mathrm{K}$ pixels, several of them being larger than $100000 \mathrm{~km}^{2}$. As expected from the OCS definition, subtype Ia and IIa cloud com- plexes move faster than MCSs (Fig. 4b). The median speed values for all 61 (42) OCSs (MCSs) are 13.5 $\mathrm{m} \mathrm{s}^{-1}\left(7.7 \mathrm{~m} \mathrm{~s}^{-1}\right)$. The value for the OCSs is somewhat on the lower side of previous estimates for similar-type line squall systems over West Africa $\left[15 \mathrm{~m} \mathrm{~s}^{-1}\right.$ for disturbance lines in the Guineo-Sudanian zone in June 


\section{Type I}

\section{(a)}
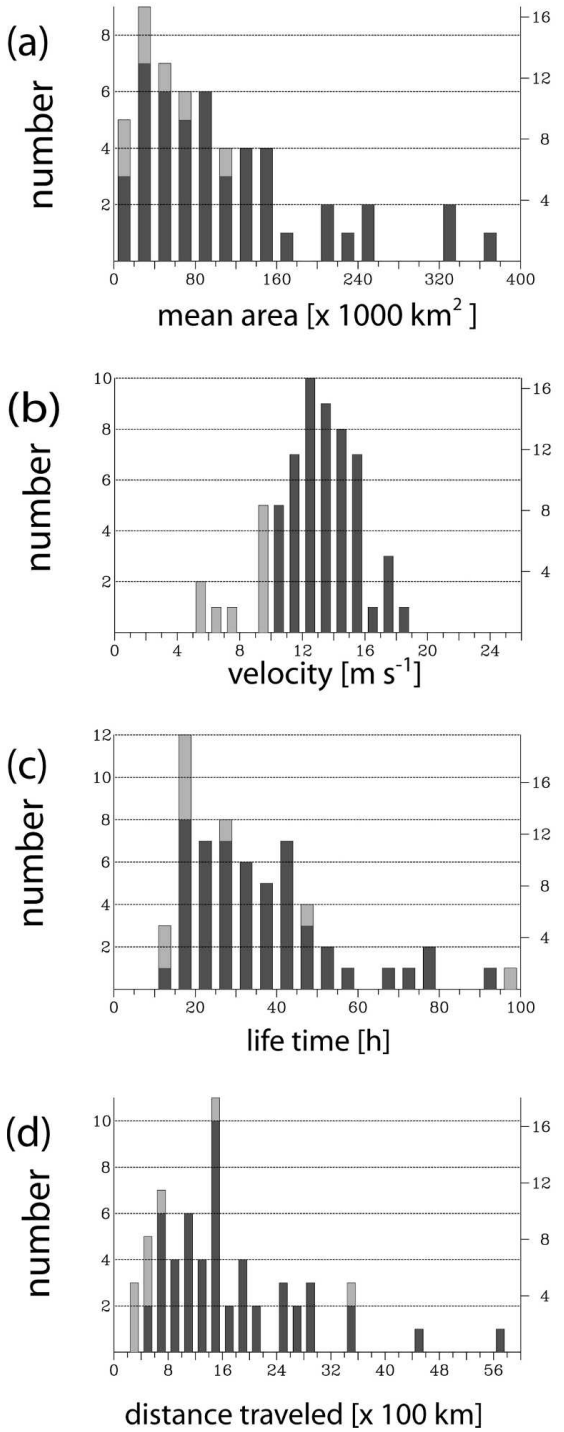

Type II
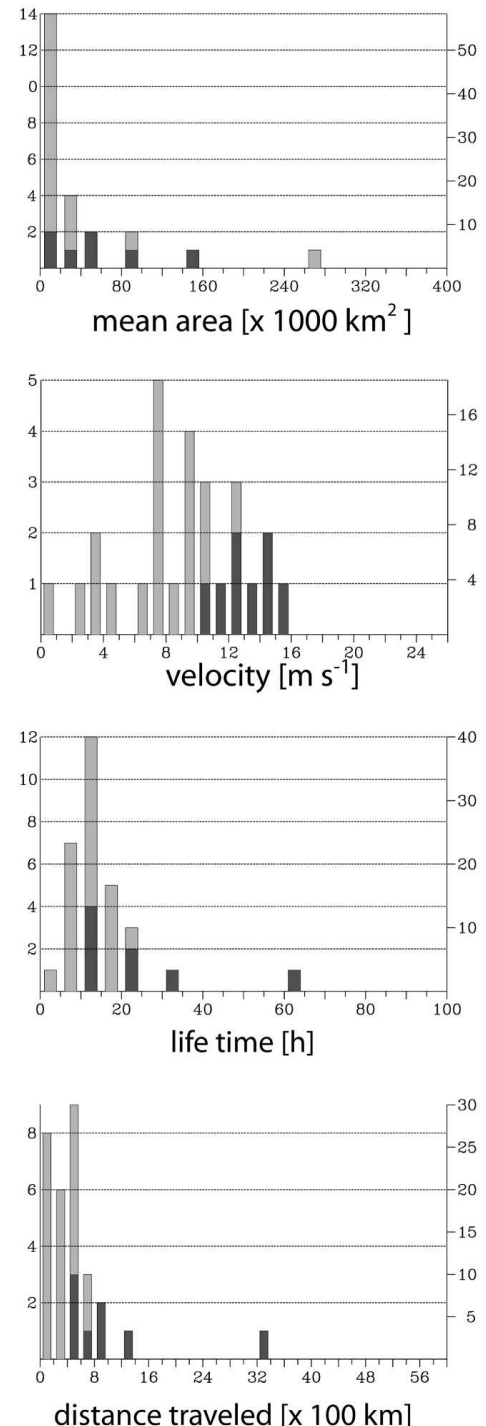

Type III
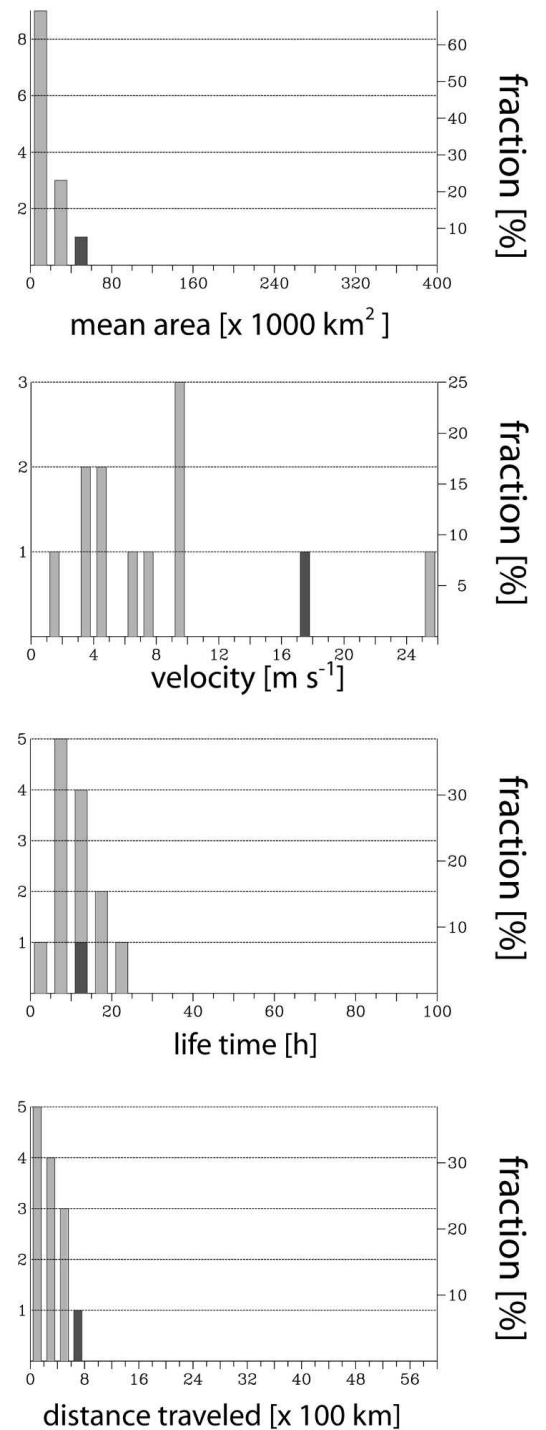

FIG. 4. Number and percentage of all cloud systems belonging to types I (advective), II (local), and III (vortex type) as a function of mean area with regard to $233-\mathrm{K}$ brightness temperatures, (b) propagation speed with regard to $213 \mathrm{~K}$, (c) liftetime with regard to $233 \mathrm{~K}$, and (d) the distance traveled with regard to $233 \mathrm{~K}$. Dark (light) gray shading within the bars refers to OCSs (MCSs).

1955 from Eldridge (1957); $15 \mathrm{~m} \mathrm{~s}^{-1}$ for 162 mostly Sahelian disturbance lines during GATE from Aspliden et al. (1976); $16 \mathrm{~m} \mathrm{~s}^{-1}$ for 15 SLs over the Sahel from Tetzlaff and Peters (1988); $15 \mathrm{~m} \mathrm{~s}^{-1}$ for 157 SLs in the central Sahel between $2.5^{\circ} \mathrm{W}$ and $14^{\circ} \mathrm{E}$ in August 1985 from Rowell and Milford (1993); and $15 \mathrm{~m} \mathrm{~s}^{-1}$ for 344 SLs from FR03]. Note, however, that differences in the translation speed can also be caused by its determination techniques.

With respect to lifetime, Fig. $4 c$ reveals that type I systems are longer lived than either type II or type III systems. The advective OCSs, for example, frequently have a life cycle from 15 to $60 \mathrm{~h}$. It shall be pointed out, however, that our selection criteria for advective type I systems will favor the selection of better organized and, thus, longer-lived systems in this cloud category. In contrast, type II and III systems rarely last longer than $20 \mathrm{~h}$. Not surprisingly, subtype Ia systems can travel as far as $3500 \mathrm{~km}$ from their origin (Fig. 4d). By comparison, the Sudanian SL case investigated by Chong et al. (1987) lasted about $36 \mathrm{~h}$ on its journey from Nigeria to Guinea, a distance of nearly $2000 \mathrm{~km}$. The median value for all OCSs is $1412 \mathrm{~km}$, whereas it is only $339 \mathrm{~km}$ for all MCSs. Thus, two general findings can be high- 
(a)

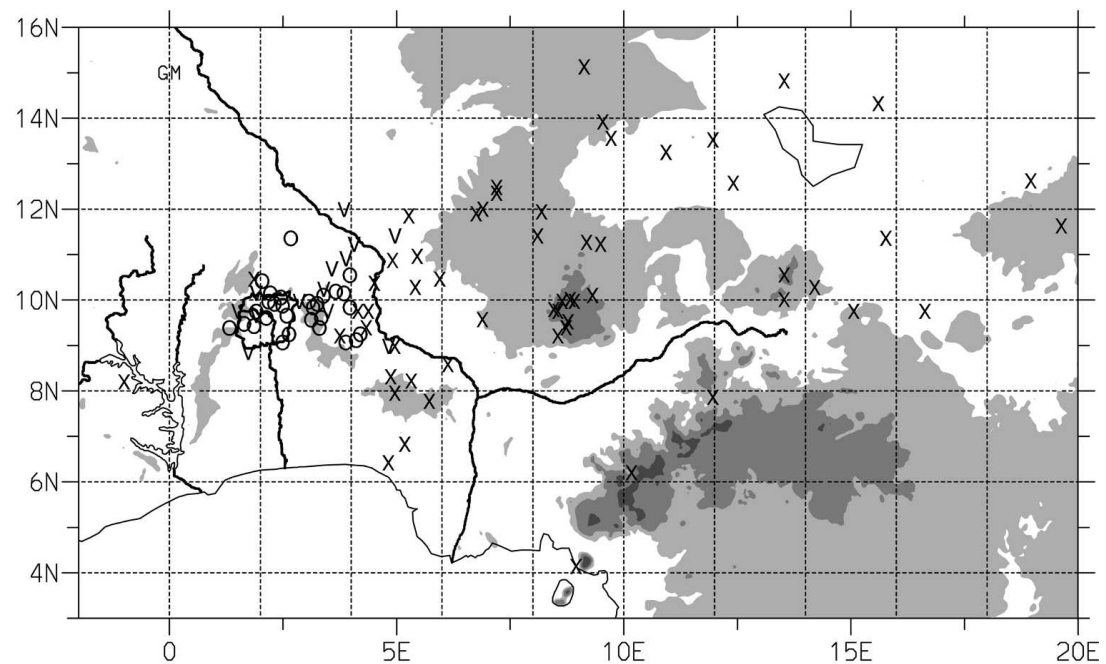

(b)

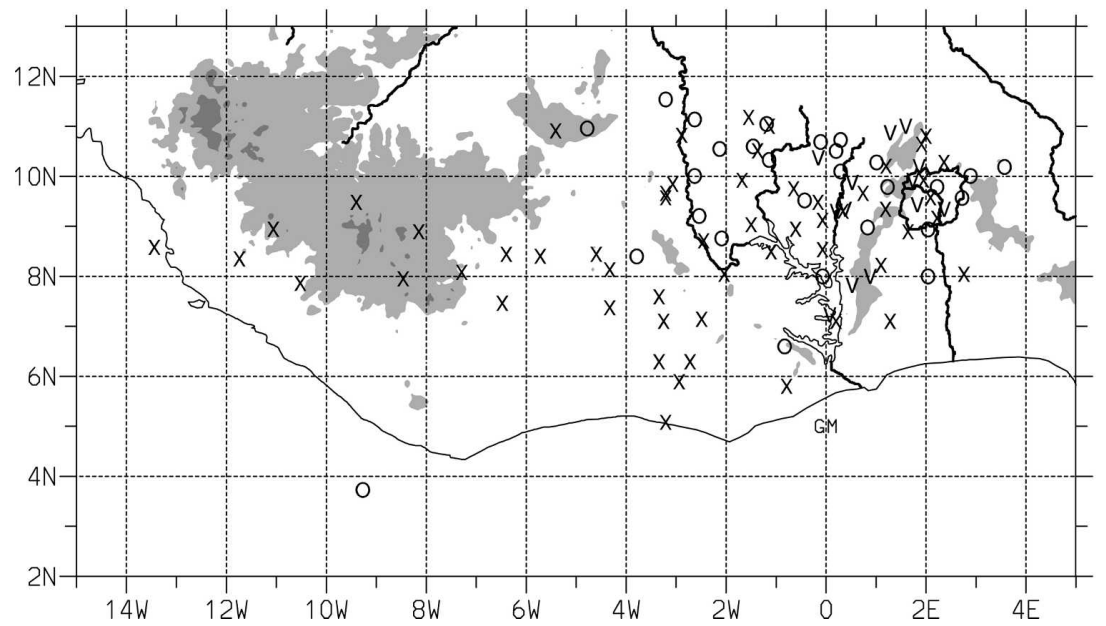

FIG. 5. (a) Location points of the first identification of advective (crosses), local (circles), and vortex MCSs/OCSs (v-shaped symbols) in half-hourly Meteosat IR satellite imagery. Also shown are the locations of the UOV, large rivers, lakes, and orography. The shading of orography depicts elevated terrain higher than 400 (light gray), 800 (medium gray), and $1500 \mathrm{~m}$ (dark gray). (b) Same as (a) but for lysis points. Four genesis and six lysis points are outside the map.

lighted here: 1) MCSs are smaller, slower, and shorterlived systems; and 2), when compared to the advective OCSs statistics, the UOV box does not seem to be a genesis region of very long-lived and large OCSs (subtype IIa) as those reaching the area from the east.

The latter conclusion is further substantiated in Fig. $5 \mathrm{a}$, which displays the points of origin of both OCSs and MCSs for all three major categories (types I-III). It is seen that the advective (type I) OCSs often originate over the Nigerian Jos Plateau (cf. Fig. 1a). FR03 also noted a maximum of SL genesis over and to the west of this plateau region. The lysis points of type I systems in Fig. $5 \mathrm{~b}$ corroborate the above-noted finding that these systems are, in contrast to the local type II, often traveling more than $1000 \mathrm{~km}$ in the zonal direction. Thus, it is concluded that the central Nigerian Highlands are a "birth region" of many long-lived OCSs and MCSs, whereas those developing over the UOV are shortlived systems traveling not too far downstream (Fig. 5b). FR03 (their Fig. 7) and Vollmert et al. (2003, their Fig. 10) showed that during the 1998 and 1999 rainy seasons, a SL lysis maximum occurred over and just to the west of the UOV. Figure 5b indicates several dissipations of advective and local types just downstream of the UOV. The above-noted studies also found that the UOV was not a favorable region of SL formation. 


\section{b. Cloud and rainfall statistics}

The rainfall accumulation in the UOV for each subtype during March-October 2002 is given in Fig. 6b, together with each subtype's fraction of the total rainfall. The systems included in this figure appear in Table 2 , row 3 . It is seen that $50 \%$ of the total rain can be attributed to advective OCSs. The only other subtype whose contribution exceeds $10 \%$ are local MCSs. The total contribution of the 49 OCSs rainfall events (i.e., sum of subtypes Ia, IIa and IIIa, see row 3 in Table 2) to the 2002 UOV network rainfall is $56 \%$. This is a conservative estimate since a contribution from OCSs to the annual rainfall is to be expected in the "mixed" (i.e., an UOV rainfall event was caused by a combination of two or more subtypes) and the "unclassified" categories. Cloud clusters of the latter class were either too localized or westward-traveling OCSs that only touched a small part of the UOV. For the same reasons, the contribution of MCS-related rainfall (i.e., subtypes $\mathrm{Ib}$, IIb, and IIIb) to the UOV rainfall in 2002 was at least $26 \%$.

Figure $6 \mathrm{~b}$ shows the diurnal cycle of UOV-accumulated rainfall by each of the three main types of convective systems as defined in Table 2, row 2. It is seen that precipitation amounts by the advective systems (type I) exhibit a primary peak between 0100 and 0500 UTC, with a broad secondary maximum between 1800 and 2400 UTC. Local time in Benin is one hour ahead of UTC. These systems are most inactive from 1300 to 1700 UTC. The primary peak after midnight is explicable by the preferred afternoon genesis region of OCSs, the Jos Plateau, its distance to the UOV, and the propagation speed of OCSs of about $14 \mathrm{~m} \mathrm{~s}^{-1}$. The secondary peak stems from OCSs and MCSs that form along the Niger Valley and the Oshogbo Hills and reach the UOV in the early night hours (cf. Figs. 1 and 5a).

The local type II systems display a narrow rainfall peak between 1800 and 2000 UTC that is comparable to the amount of rainfall coming from type I systems at this time of the day. Type III systems contribute very little rain to the total and show no diurnal cycle (Fig. $6 b)$. As a consequence of the diurnal cycles of types I and II, the total accumulation of rain maximizes between 1800 and 2100 UTC, with a secondary peak from 0100 to 0500 UTC. The former peak is also evident from the percent coverage of convective cloud during GATE, as shown in Fig. 2 of McGarry and Reed (1978). The authors also note a maximum of convective cloud cover shortly after midnight due to the maximum development of organized cloud cluster that has been initiated in the afternoon hours. This diurnal cycle of organized convection is observed over other tropical
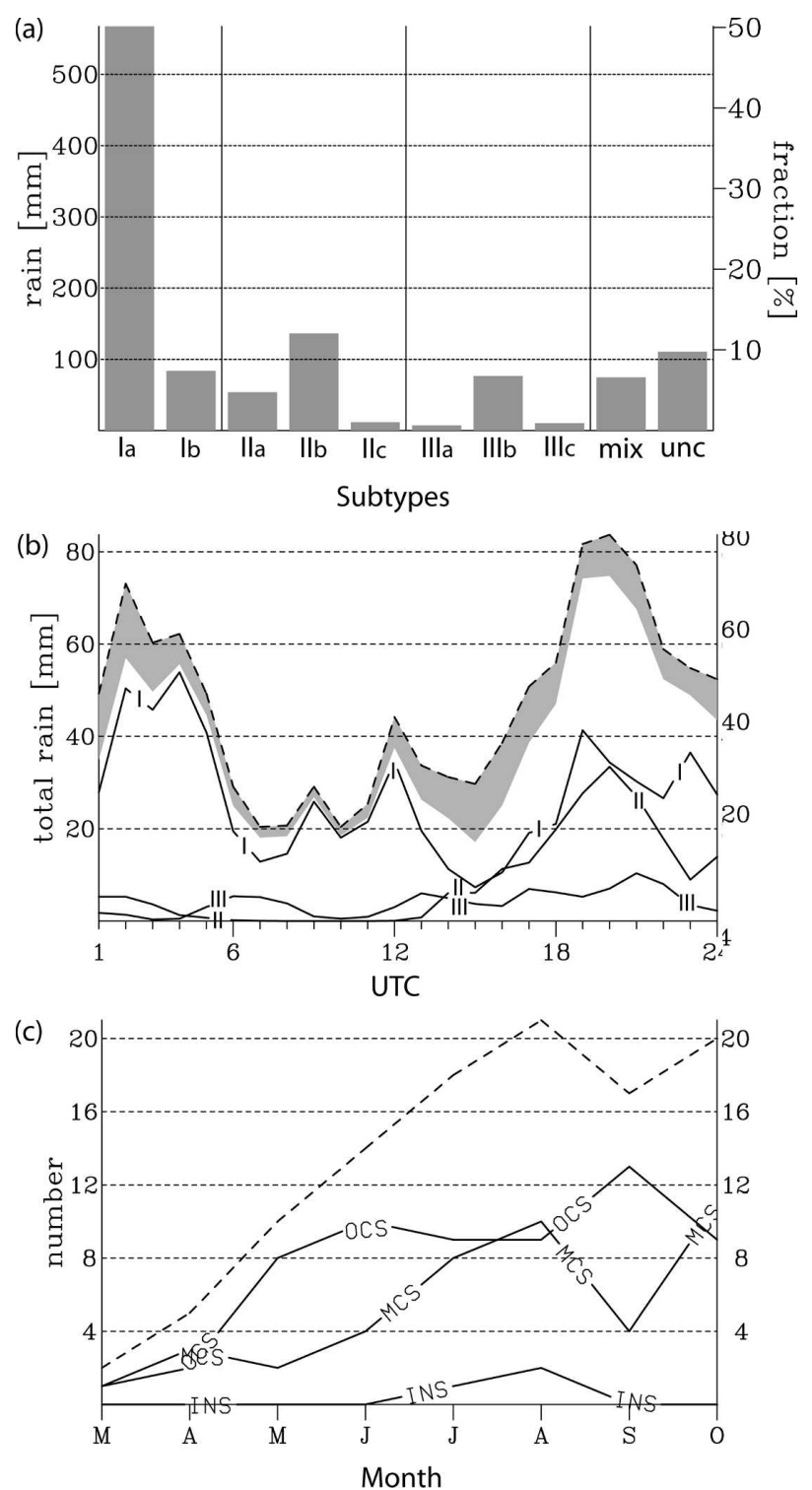

FIG. 6. (a) Accumulated UOV rainfall and the percentage of the total March-October 2002 rainfall for each subtype. The bars labeled "mix" and "unc" show the fraction of seasonal UOV rainfall that was due to a combination of two or more different subtypes, or that has not been classified, respectively. The members of the unc sample failed to be UOV rainfall events (cf. section 3b). (b) The solid curves display the diurnal cycle of hourly, accumulated rainfall by each of the three types I (advective), II (local), and III (vortex type). The dashed line represents the sum of UOV rain accumulation. The gray shaded area below the dashed line indicates the contribution of the unc class and mixed-type events to the total rainfall. (c) Seasonal cycle (Mar-Oct 2002) of the monthly numbers of MCSs, OCSs, and instability storms (INSs). The dashed line displays the sum of number of cloud systems.

land areas (Nesbitt and Zipser 2003). However, the secondary peak from the UOV rainfall network is shifted toward the morning hours due to its zonal distance to the main genesis region of advective OCSs. Note that 
the rainfall sum of types I, II, and III explains less than $70 \%$ of the total precipitation around 1500 UTC. At this time, small-scale instability showers that fail to be an UOV rainfall event are frequent and widespread.

The seasonal cycle of the number of OCSs (subtypes Ia, IIa, and IIIa), MCSs (subtypes Ib, IIb, and IIIb), and instability showers (subtypes IIc and IIIc) is shown, together with their sum, in Fig. 6c. Throughout most of the season, the number of OCSs is greater than the number of MCSs, especially in May and June, as well as in September. The number of MCSs and instability showers peaks around the height of the monsoon season in August, while the number of OCSs is greatest in September. The total number of rainfall events increases until August and stays high into October. As mentioned at the beginning of section 4, the 2002 rainy season started somewhat drier than normal and ended wetter than normal. Thus, the first OCS peak in June may not be as pronounced in 2002 as in a normal year, and a bimodal distribution of OCS frequency might be a climatological feature of this region.

Composites of 6-min rain rates versus rainfall duration averaged over all operating rain gauges in the UOV are shown in for the three subtypes (Ia, IIb, and IIIb) that accounted for the largest number of rainfall systems (Table 2, row 3). Not surprisingly, subtype Ia has the highest intensities of the three subtypes shown. In the first hour, subtype Ia produces $10.4 \mathrm{~mm}$ of rain during the convective part of an OCS. By comparison, Peters and Tetzlaff (1988), in their composite of 17 Sahelian SLs, had an average rainfall rate of $11 \mathrm{~mm} \mathrm{~h}^{-1}$. Moreover, the UOV network average rainfall intensity and duration in the stratiform part of the OCSs (Fig. 7a) are comparable to the characteristic values of $4 \mathrm{~mm} \mathrm{~h}^{-1}$ intensity and of 2-3-h duration, found for the two SLs during the COPT 81 experiment in the Sudanian zone of Ivory Coast (Chong et al. 1987; Roux 1988). Results from subtype IIb (local MCSs) show that rainfall from these systems is less intense in the convective and stratiform parts, but lasts somewhat longer than the rain from subtype Ia systems (Fig. 7b). This may be related to a slower propagation speed and lesser degree of organization. In this context, it must be emphasized that the intensity graphs reflect the rainfall intensity evolution in the UOV network mean, and not for a single rain gauge. Subtype IIIb systems have the longest duration of the three subtypes shown (Fig. 7c); in one case, rain lasted $13 \mathrm{~h}$ in the UOV network. Also, the rain in subtype IIIb falls more irregularly than it does from subtypes Ia and IIb because convective cells in the former are not as well organized. Instability showers (not shown) have the shortest duration of $1-2 \mathrm{~h}$.
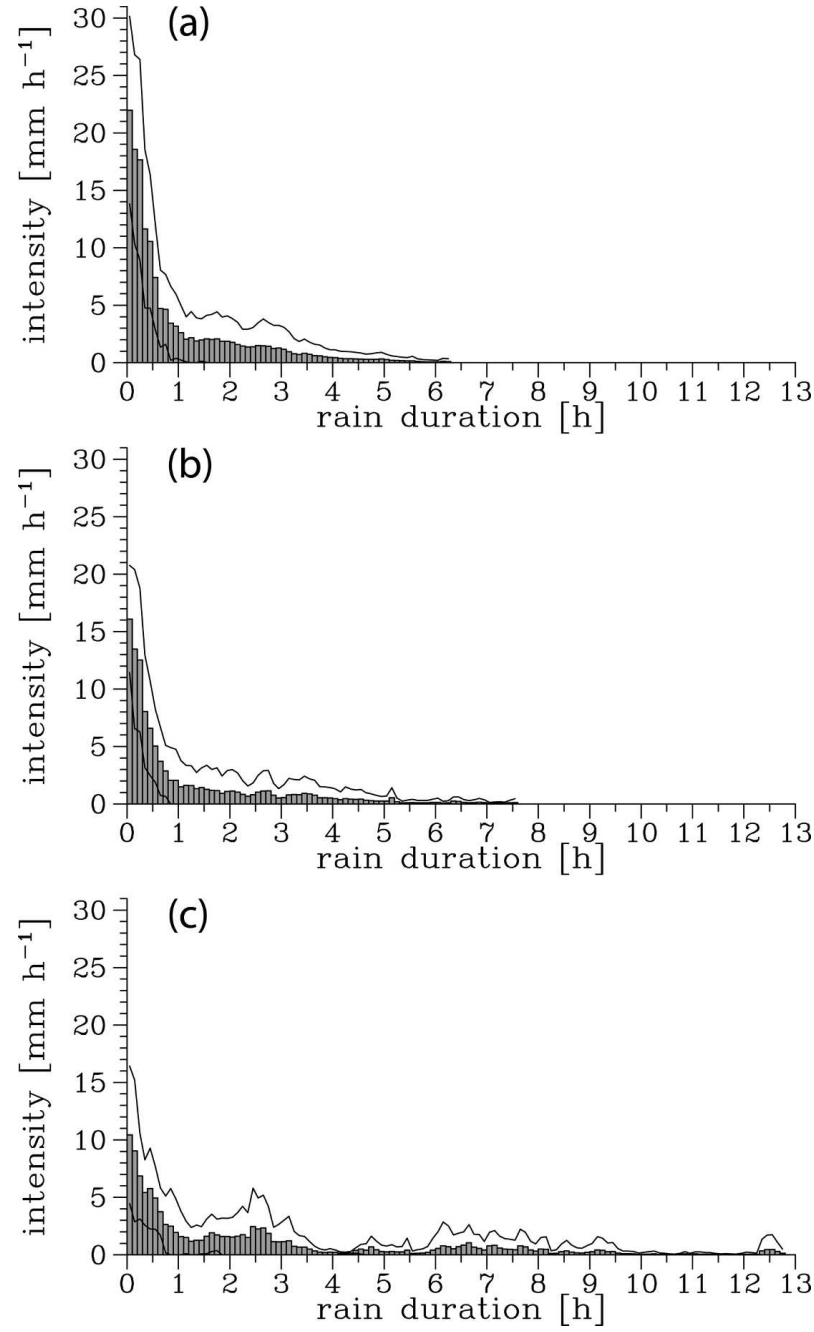

FIG. 7. (a) Composites of 6-min rain rates vs rainfall duration averaged over all operating rain gauges in the UOV and all subtype Ia (advective OCS) events. (b) As in (a) but for subtype IIb (local MCS). (c) As in (a) but for subtype IIIb (vortex MCS) events. Also shown are the 1 std dev curves (thick lines).

\section{c. Environmental changes accompanying rain system passage}

Several composited variables are discussed below that depict the environmental conditions in the tropospheric column above Parakou before and after the passage of precipitating systems that were caused by the same rainfall subtype (see Table 2, row 3, which represents the sample used to construct the profiles in Figs. 8 and 9). The following criteria had to be met before a sounding was used for the prerainstorm composites: 1) the fractional coverage of clouds with brightness temperatures below $233 \mathrm{~K}$ was less than $20 \%$ over the UOV box in the hour before and after the sonde was launched at Parakou; 2) the launch took place in 

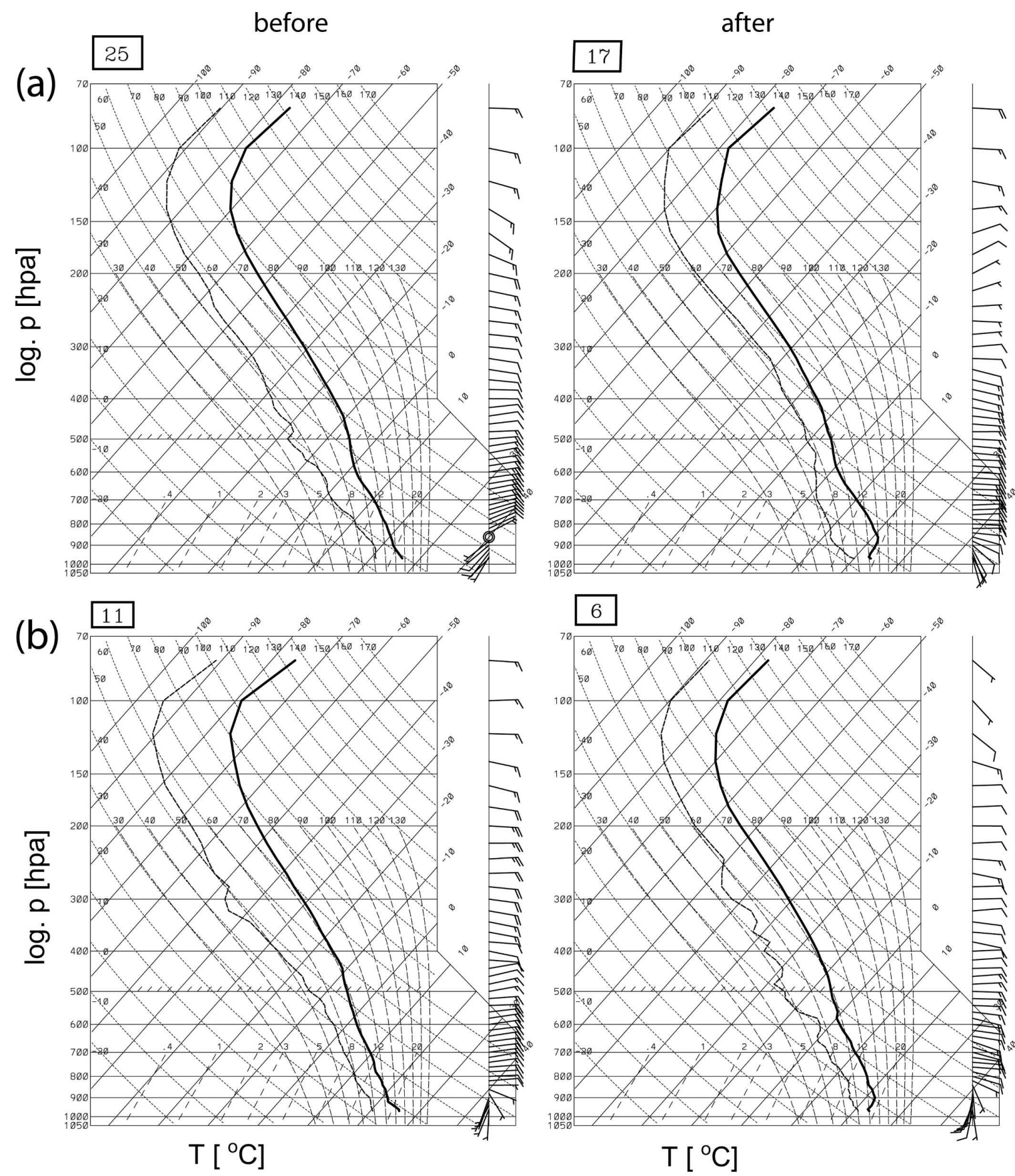

FIG. 8. (a) Skew $T-\log p$ diagrams of composite soundings at Parakou of temperature (thick solid line), dewpoint temperature (dashed line), and wind for subtype Ia (advective OCS) (left) before and (right) after passage of a rain system. (b) As in (a) but for subtype IIb (local MCS). The vertical resolution is $20 \mathrm{hPa}$. The boxed numbers in the upper left corners indicate the numbers of all soundings available for compositing.

the time interval beginning $6 \mathrm{~h}$ before the UOV rainfall event started and ending with the time of the maximum network-mean rainfall intensity. The first criterion ruled out that rains from the larger clusters that crossed through the UOV affected the prestorm sounding at
Parakou. The second criterion serves two purposes: first, it determined the earliest prerainstorm soundings possible, and, second, meaningful soundings were included when a few gauges recorded light rainfall before the actual cloud-cluster-related rainfall commenced. 
before
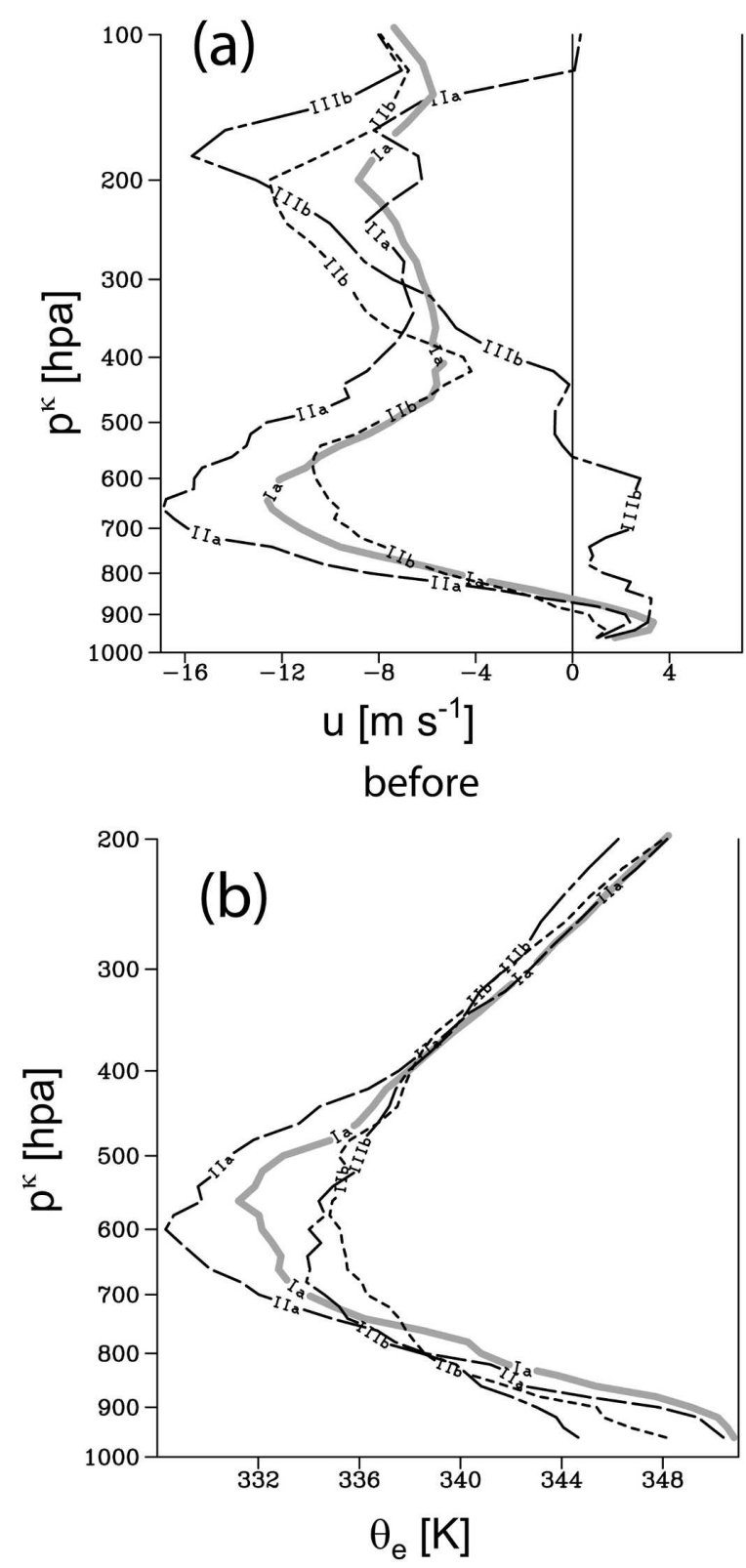

after
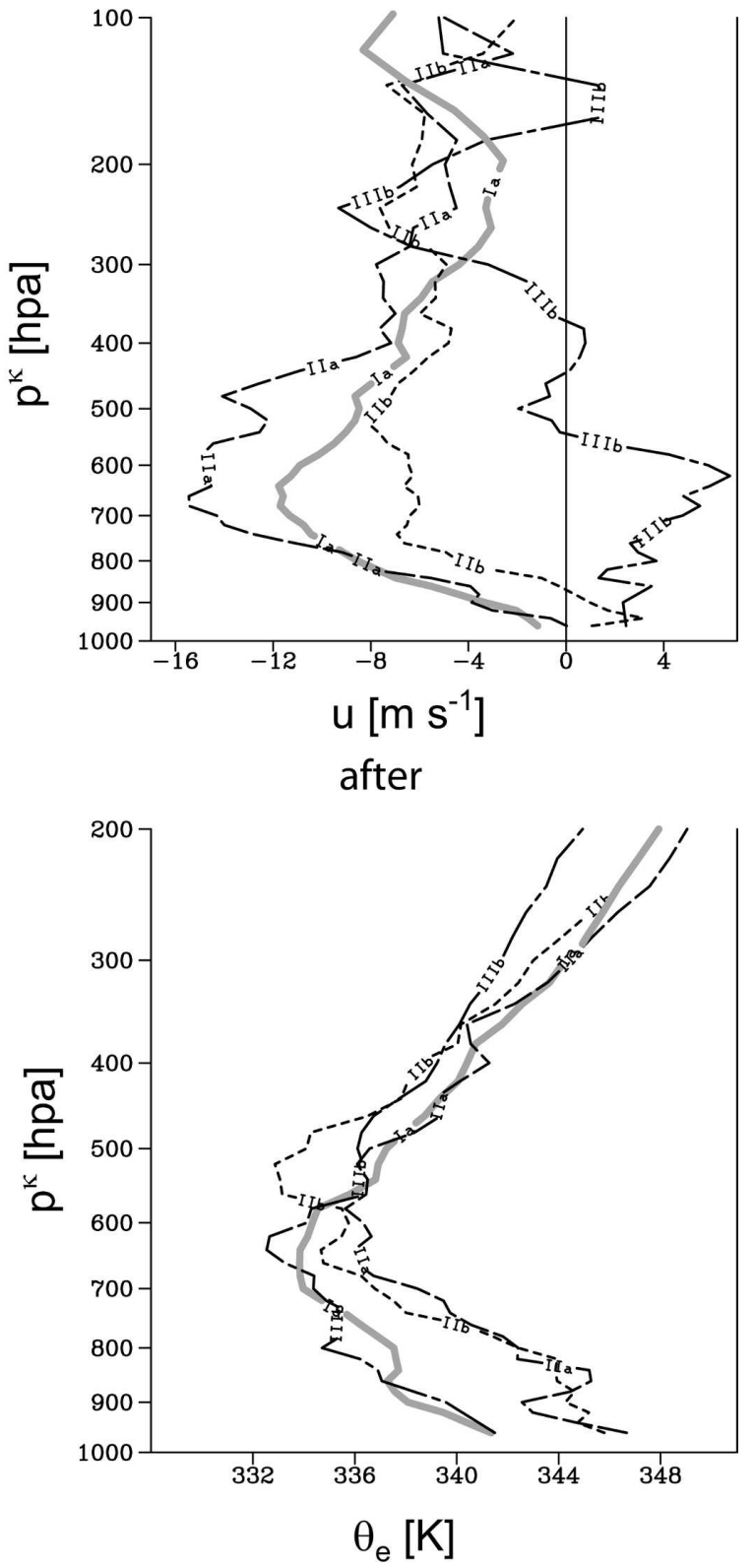

FIG. 9. (a) Composite vertical profiles based on radiosonde data of the zonal wind $u$ and (b) equivalent potential temperature $\theta_{\mathrm{e}}$ before and after rain events. The profiles of subtypes Ia (advective OCS, gray), IIa (local OCS, large dash), IIb (local MCS, small dash), and IIIb (vortex MCS, large dash-dot) are displayed. The vertical resolution is reduced to $20 \mathrm{hPa}$.

The only postrainstorm soundings used were those where 1) rain was observed at the sounding location and 2) the ascent happened within the $6 \mathrm{~h}$ after the maximum network rainfall was observed. The numbers of soundings used to calculate the mean soundings are given in column 2 of Table 3 .

To begin with, the composite soundings at Parakou for subtypes Ia and IIb, both before and after these systems pass by the station, are displayed in skew $T-\log p$ diagrams in Figs. 8a and 8b. These two subtypes were selected because they were the two largest contributors to the annual rainfall totals (Fig. 6) and also have the largest number of soundings available for compositing (see boxed-in number at upper-left-hand corner of each sounding). The soundings for subtypes Ia show that there is a drying out of the lower tropo- 
TABLE 3. Thermodynamic features by subtype before and after rain events, where "No." is the number of soundings available, CAPE is pseudoadiabatic convective available potential energy for an ascending parcel representative of the surface-925-hPa layer, and CIN is pseudoadiabatic convective inhibition.

\begin{tabular}{|c|c|c|c|c|c|c|c|c|c|c|}
\hline \multirow[b]{2}{*}{ Subtype } & \multicolumn{5}{|c|}{ Before } & \multicolumn{5}{|c|}{ After } \\
\hline & No. & $\begin{array}{c}\text { CAPE } \\
\left(\mathrm{J} \mathrm{kg}^{-1}\right)\end{array}$ & $\begin{array}{c}\mathrm{CIN} \\
\left(\mathrm{J} \mathrm{kg}^{-1}\right)\end{array}$ & $\begin{array}{l}\text { LFC } \\
(\mathrm{hPa})\end{array}$ & $\begin{array}{l}\text { LZB } \\
(\mathrm{hPa})\end{array}$ & No. & $\begin{array}{c}\text { CAPE } \\
\left(\mathrm{J} \mathrm{kg}^{-1}\right)\end{array}$ & $\begin{array}{c}\mathrm{CIN} \\
\left(\mathrm{J} \mathrm{kg}^{-1}\right)\end{array}$ & $\begin{array}{l}\mathrm{LFC} \\
(\mathrm{hPa})\end{array}$ & $\begin{array}{l}\text { LZB } \\
(\mathrm{hPa})\end{array}$ \\
\hline Ia & 25 & 1175 & -56 & 731 & 164 & 17 & -282 & -300 & 658 & 525 \\
\hline $\mathrm{Ib}$ & 6 & 650 & -20 & 816 & 204 & 3 & 187 & -72 & 810 & 278 \\
\hline IIa & 6 & 1208 & -54 & 735 & 169 & 5 & 137 & -132 & 751 & 326 \\
\hline IIb & 11 & 665 & -34 & 782 & 203 & 6 & 121 & -140 & 684 & 286 \\
\hline IIc & 1 & 3 & -21 & 941 & 641 & 1 & 327 & -12 & 886 & 219 \\
\hline IIIa & 1 & 557 & -19 & 765 & 199 & 0 & - & - & - & - \\
\hline IIIb & 9 & 323 & -39 & 690 & 238 & 1 & 78 & -55 & 934 & 370 \\
\hline IIIc & 1 & 1287 & -12 & 922 & 177 & 0 & - & - & - & - \\
\hline
\end{tabular}

sphere and a moistening of the mid- to upper troposphere with passage of advective OCSs. A nearisothermal, stable layer also forms near the surface after the OCSs pass due to a cooling of the surface temperature. These conditions are typical of other types of active convection systems (e.g., SLs, disturbance lines) and most likely are a result of evaporational cooling and the related cold downdrafts in the lower troposphere, which also dry out the atmosphere (see, e.g., Hamilton and Archbold 1945; Zipser 1977; Kamara 1986; Chong et al. 1987; Roux 1988; Redelsperger et al. 2002). In addition, the moistening of the middle and upper troposphere is probably an indication of precipitating particles in and below the anvil region. Ahead of the OCSs, southwesterly monsoonal winds occur from the surface up to about $850 \mathrm{hPa}$, then they abruptly shift to northeasterly and easterly above that level (Fig. 8a, left panel). After OCS passage, easterly winds occur throughout the troposphere (Fig. 8a, right panel) suggesting that a downward transport of easterly momentum has been accomplished within the downdrafts of the OCSs (e.g., Thorncroft et al. 2003). Figure $8 \mathrm{~b}$ shows the composite soundings at Parakou before and after the passage of local MCSs. Contrary to the advective OCSs, there is very little change with passage in the profiles of temperature, dewpoint temperature, and wind direction. Note, however, that a shallow stable layer develops near the surface after the MCSs pass by. This was also observed for the OCSs, but the layer was deeper for the latter. Notice, however, that the subtype IIa systems are more moist than subtype Ia events in the $800-500-\mathrm{hPa}$ layer before the rainfall started.

Profiles of the zonal wind $u$ and the equivalent potential temperature $\theta_{\mathrm{e}}$, representing the vertical structure of the atmosphere at Parakou, both before and after the passage of four subtypes of rainfall systems
(Ia, IIa, IIb, and IIIb), are shown in Fig. 9. It is seen from Fig. 9a (left panel) that the advective (subtype Ia) and local (subtype IIa) systems were associated with the largest prestorm, low-level wind shear. It must be emphasized that the IIa systems (local OCSs) only occurred in April-May and in September-October. During these months, the AEJ is often overhead of the UOV, which accounts for the strong easterlies at 650 hPa. The local MCSs (subtype IIb) that were most frequent at the peak of the monsoon season exhibit a weaker low-level wind shear, but a stronger tropical easterly jet (TEJ). The latter is strongest during the vortex-type MCSs that are also characterized by a missing low-level wind shear and AEJ (cf. section 3b). A close examination of the postevent profiles in Fig. 9a (right panel) reveals that, for subtypes Ia and IIa, a downward transport of easterly momentum took place in the lower troposphere after they passed by Parakou. The transport by subtype Ia systems is much greater than its subtype IIa counterpart. Also, both subtypes show a weakening of the upper-tropospheric easterly jet after passage, indicating the presence of westerly anvil flow aloft. For subtype IIb, both the AEJ and upper-tropospheric jet maxima decay after passage of the local MCSs, and there is uniform weak easterly flow from 700 to $150 \mathrm{hPa}$. However, as mentioned above, the low-level westerly flow is not replaced after the passage of the locally developing MCSs.

Prestorm profiles of $\theta_{\mathrm{e}}$ (Fig. 9b, left panel) reveal much lower values between 750 and $400 \mathrm{hPa}$ for the OCSs (Ia and IIa). This is related to a drier midtroposphere (not shown). The lowest $\theta_{\mathrm{e}}$ values occur for the OCSs that develop over the UOV box in the pre- and postmonsoon seasons (subtype IIa). At this time, intrusions of dry midlevel Saharan air layers frequently occur. In contrast, the local MCSs (IIb) develop in a much moister troposphere at the height of the rainy season. 
This is also true for the nine composited MCSs that occurred during the presence of a midlevel, quasistationary vortex (IIIb). As mentioned earlier for subtype Ia, the surface temperature after passage of advective OCSs underwent strong cooling, with warming and drying of the air in the lower troposphere and cooling and moistening in the middle and upper troposphere. These features are substantiated even more in the profiles of $\theta_{\mathrm{e}}$ (Fig. 9b, right panel).

A more thorough examination of instability is summarized in Table 3, which shows values of pseudoadiabatic convective available potential energy (CAPE), convective inhibition (CIN), level of free convection (LFC), and level of zero buoyancy (LZB), averaged for each subtype investigated in this study. In general, the CAPE, CIN, LFC, and LZB values for the advective (Ia) and local (IIa) OCS systems are the highest, reflecting an environment that favors, in combination with the high low-level shear, the generation of SLs. The mean CAPE value of subtypes Ia (advective OCSs) is $1175 \mathrm{~J} \mathrm{~kg}^{-1}\left(-282 \mathrm{~J} \mathrm{~kg}^{-1}\right)$ before (after) the OCSs passage at Parakou. The highest individual value of CAPE in this study, out of the 25 subtype Ia cases, was approximately $3000 \mathrm{~J} \mathrm{~kg}^{-1}$. This compares well with the value of $2810 \mathrm{~J} \mathrm{~kg}^{-1}$ for a strong SL during COPT 81 (Roux 1988). Redelsperger et al. (2002) give CAPE values of 1258 and $1921 \mathrm{~J} \mathrm{~kg}^{-1}$ from two ascents a few hours ahead of an individual SL during the Hydrological Atmospheric Pilot Experiment (HAPEXSahel). After passage of the SL, the value dropped to 25 $\mathrm{J} \mathrm{kg}^{-1}$. The MCSs of subtype Ib and IIb had a CAPE value being half that of the corresponding OCSs (Table 3). They also have lower LFCs and LZBs. This corroborates the earlier findings that these rainfall events occurred in a less-sheared and moister environment. Finally, Table 3 shows that the nine MCSs that occurred during the low-level vortex situation had a very low value of CAPE (323 J kg-1) and the highest LFC (690 $\mathrm{hPa}$ ). This might indicate that low-level convergence and/or upper-level divergence at the TEJ level were necessary to release the instability.

\section{d. Relationship of rainfall systems to AEWs}

While several AEWs start to become discernible in streamline charts as far east as $20^{\circ} \mathrm{E}$ (FR03; Fink et al. 2004), they remain of weak amplitude until they traverse the GM. The IMPETUS 2002 experimental campaign now permits a more regionally focused investigation to be conducted on the relationship between AEW phases and the life cycles of advective type I cloud systems. FR03 found that an AEW trough region generally consists of two paired, cyclonic vortices; a northerly cyclonic anomaly traveling westward in the dry zone between $17^{\circ}$ and $19^{\circ} \mathrm{N}$ and a southerly counterpart moving simultaneously through the rainy zone between $8^{\circ}$ and $10^{\circ} \mathrm{N}$. Therefore, all northerly and southerly AEW vortices have been tracked using the manual tracking method described in FR03. Next, the longitudinal positions of the centers of gravity of the cloud systems (cf. section 3a) relative to the vortex centers of the northern and southern AEWs during the system's initiation, arrival in the UOV, and dissipation have been plotted. The corresponding six scatter diagrams are displayed in Fig. 10. Note that the 61 systems from Table 2, row 1 (i.e., advective OCSs and MCSs), were used to construct the diagram, but only 31 of them occurred when an AEW was present in the weather charts.

Figure 10a shows that advective OCSs and MCSs mainly initiate east of the AEW cyclone centers, with a preferred location in the southeast (northeast) quadrant of the northern (southern) vortices. In the ensemble mean (black dots in Fig. 10a), the cloud system's genesis locations are displaced $3^{\circ}-4^{\circ}$ longitude east of the paired vortex centers. Assuming a wavelength of about $2500 \mathrm{~km}$ (FR03), this corresponds to the AEW phase $5-6$, that is, the region close to the maximum southerly winds. This is in contrast to several previous studies (e.g., Payne and McGarry 1977; Kamara 1986; Peters et al. 1989; FR03) that conclude that SLs are most often developing west, that is, ahead, of the AEW trough axis. It is only in the dry Sahel region that a secondary SL genesis maximum east of the trough has been found in some studies (Burpee 1974; Duvel 1990; Mathon et al. 2002a; FR03).

By the time the type I systems reach the UOV, for both AEW vortex centers, there are about the same number of systems ahead of the vortex as behind it (Fig. 10b). An SL system typically propagates westward across West Africa about twice as fast as its accompanying AEW. Thus, it is expected from the preferred genesis locations behind the AEW vortices that they will pass through the trough region in the course of their lifetime. Such a behavior has been noted for a West African SL system in Fortune (1980). Evidently, this often happened over the UOV longitudes in 2002. Consistent with these arguments, Fig. 10c shows that many type I systems propagated far ahead of the AEW trough and dissipated far west of it. One of the many cases that were used to create the results in Fig. 10 is shown in Fig. 11. This particular example is for a subtype Ia system that first appeared near $13^{\circ} \mathrm{N}$, $13^{\circ} \mathrm{E}$ sometime before 0600 UTC 3 September 2002 (Figs. 11a and 2b). At this time, the OCS is located just 


\section{Northern AEW vortex Southern AEW vortex}
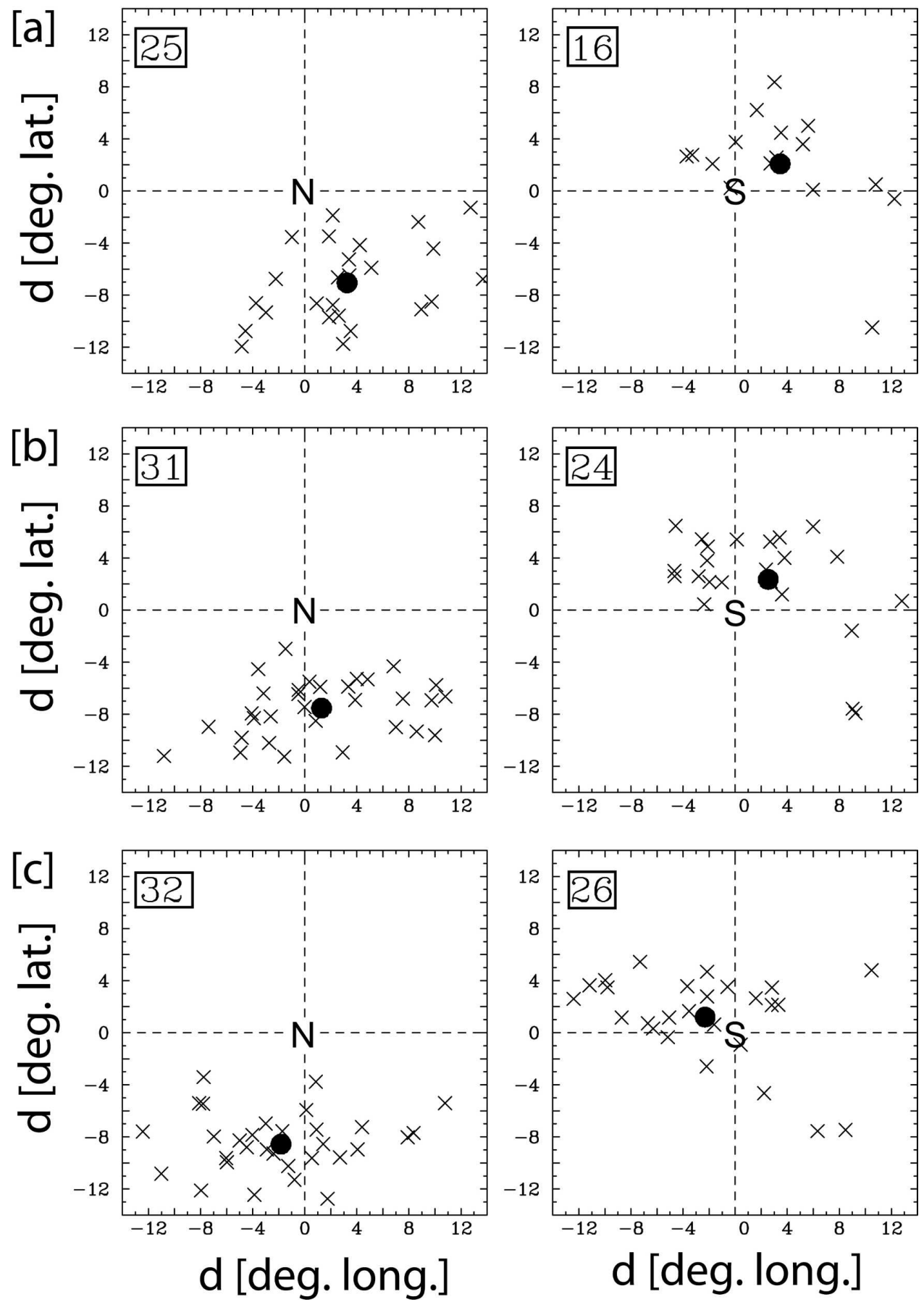

FIG. 10. Locations of the subtypes Ia (advective OCS) and Ib (advective MCS) cloud systems, based on the center of gravity of the $233-\mathrm{K}$ brightness temperature, at the time of their initiation, (b) arrival over the UOV box, and (c) dissipation. Distances are shown in degrees latitude and longitude relative to the location of the center of (left) northern and (right) southern AEWs for each category. The large black circle depicts the mean position of all systems in that particular box. The number in the upper left corner of each box represents the total number of type I (advective) systems in each box. 
(a)

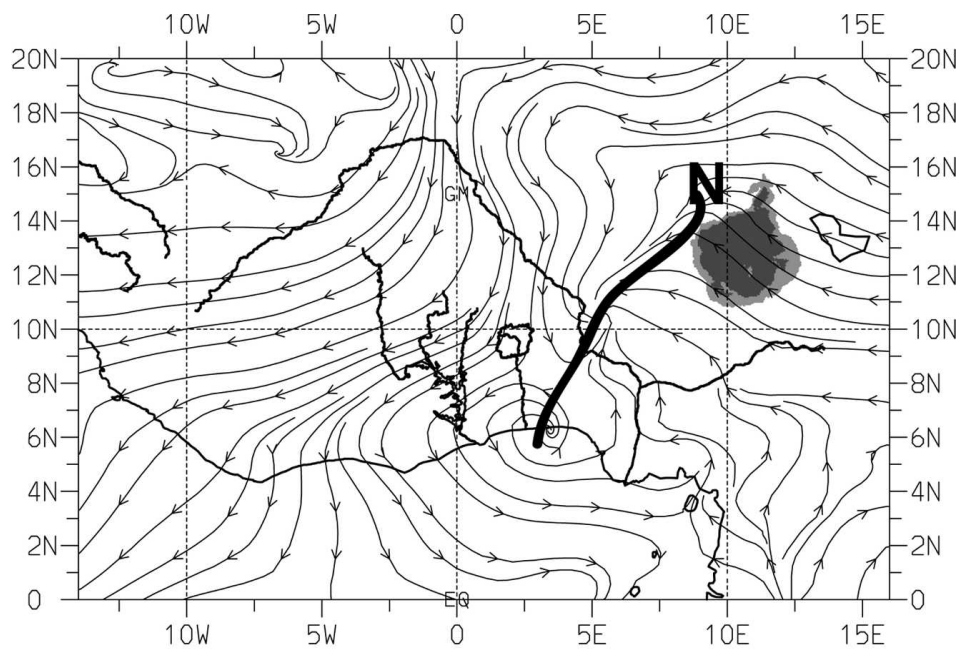

(b)

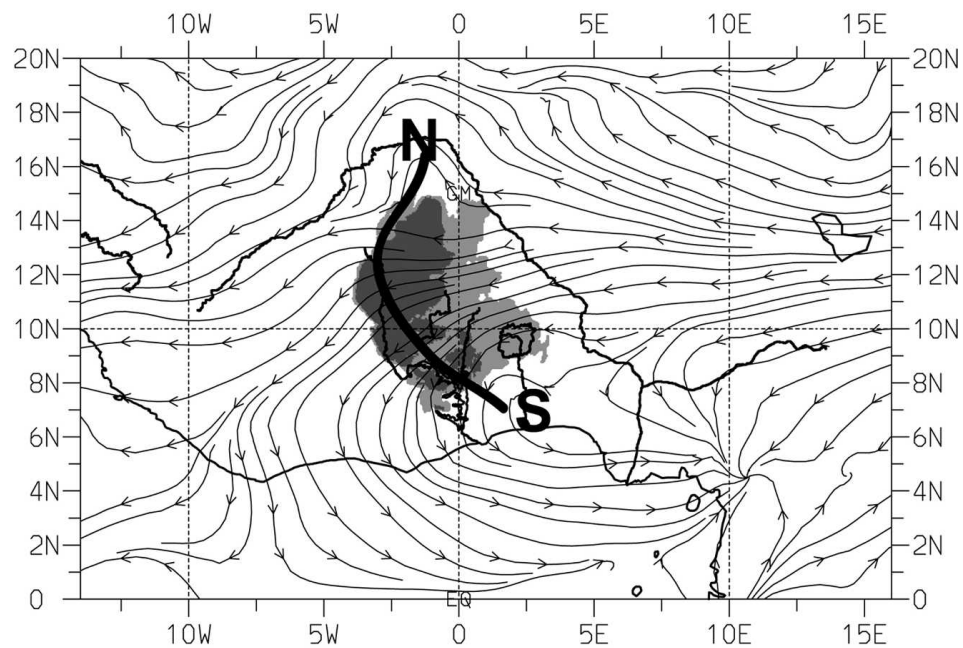

(c)

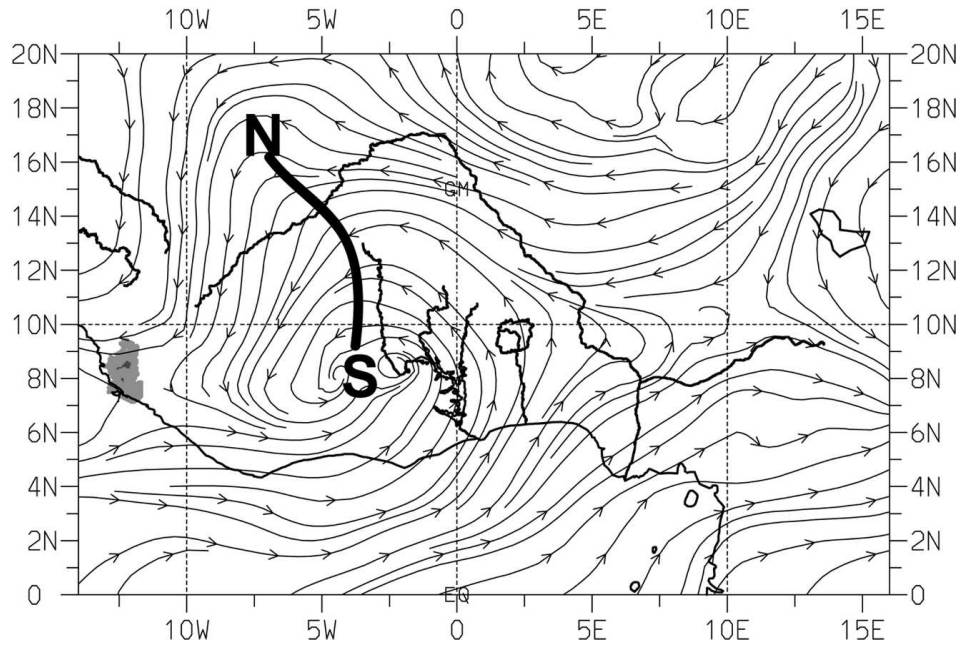

FIG. 11. (a) Streamlines on the 850-hPa surface at 0600 UTC 3 Sep, (b) 0000 UTC 4 Sep, and (c) 1800 UTC 4 Sep 2002. Also shown are the location of the UOV and the areas enclosed by the 233- (light gray) and 213-K (dark gray) brightness temperatures used to track this and all other subtype Ia (advective OCS) cloud systems. The analyzed cyclonic centers of northerly and southerly AEWs are labeled "N" and "S," respectively. The boldface AEW trough lines delineate the subjectively analyzed maximum cyclonic curvature between the two AEW vortices. 
southeast of a northerly AEW vortex (depicted by an "N" in Fig. 11a) and behind the AEW trough line. In the next $18 \mathrm{~h}$, the system moves rapidly westward, passing through the UOV, and expanding its area of active convection by a substantial amount (Figs. 11b and 2b). It is now located in the AEW trough axis area south of the northerly vortex center, but northwest of the southerly vortex center. At the last time shown (1800 UTC on 4 September), the convective system has almost dissipated completely and it has moved considerably west of the two vortex centers (Fig. 11c). This case example is typical of the long-lived, large-distance traveling OCSs depicted in Fig. 10.

\section{Summary and concluding remarks}

This paper has attempted to partition rainfall amounts over West Africa during the 2002 summer monsoon season into several of the characteristic types and subtypes of precipitating systems. A regional emphasis was on the Upper Ouémé Valley in central Benin where enhanced observations were collected in 2002. The most prominent rainfall subtype was found to be the fast-moving (median value: $13.5 \mathrm{~m} \mathrm{~s}^{-1}$ ) and highly organized convective systems that often develop far upstream over the central Nigerian highlands and arrive at the UOV after midnight. These advective OCSs (subtype Ia) accounted for at least $50 \%$ of the total rain amount. Together with the locally developing and vortex-type OCSs (subtypes IIa and IIIa) this fraction rises to at least $56 \%$. This percentage agrees well with those found in earlier studies on SLs in the Sudanian zones of Ghana (Eldridge 1957) and Nigeria (Omotosho 1985). Subtypes Ia and IIa were found to pass by or develop when a highly sheared environment with deep and dry midtropospheric Saharan air layers was present over the UOV. These systems were most frequent outside the peak of the monsoon season in July and August and, not surprisingly, displayed variations in tropospheric profiles and surface rainfall intensities characteristic for SL systems.

The present study yielded evidence that the advective OCS cloud clusters originating over the orography of central Nigeria (with altitudes in excess of $1000 \mathrm{~m}$ ) were, when compared with the OCS developing locally over the UOV, particularly extensive (median area: $82000 \mathrm{~km}^{2}$ ) and long lived (median life span: $30 \mathrm{~h}$ ). They traveled a median distance of $1418 \mathrm{~km}$ with a few subtype Ia systems lasting $2^{1 / 2}$ days and traveling a distance of more than $3000 \mathrm{~km}$ across West Africa from their region of origin. These characteristics exceed those found by other authors for disturbance lines and
SLs (Eldridge 1957; Chong et al. 1987). Other studies have pointed to the prominent SL genesis maximum over the Jos Plateau (FR03; Omotosho 1984) and the less-favorable conditions over the Dahomey Plains in Benin (Aspliden et al. 1976; Vollmert et al. 2003). It is generally assumed that enhanced diurnal heating and reduced CIN over the orography increase the likelihood of the release of potential instabilities. However, the causes of the strong organization and downstream development of OCSs originating over central Nigeria is poorly understood. Reasons may be related to local factors (e.g., terrain height, moist static stability, and outflow) that help the developing SL attain the necessary strength of the self-sustaining mesoscale circulation. A further explanation may be related to an AEW/ OCS interaction. Several type I cloud complexes developed over the high plateau regions of central Nigeria behind the AEW trough and propagated into the region ahead of an AEW trough. Moreover, from the $50 \%$ OCSs that developed over Nigeria in the absence of an AEW, some may experience this favorable AEW phase after they cross the GM and enter a region of strong AEW growth.

The second major type of organized convection, contributing $26 \%$ to the annual UOV precipitation in 2002, termed MCSs (subtypes Ib, IIb, and IIIb) in the present study, occurred in a less-sheared and moister tropospheric environment mainly around the height of the rainy season. The level of free convection, cloud tops, and surface gusts (not shown) were lower than in the OCS cases. These MCSs were much slower $\left(8 \mathrm{~m} \mathrm{~s}^{-1}\right)$, shorter lived $(12.5 \mathrm{~h})$, and less extensive $\left(15000 \mathrm{~km}^{2}\right)$ than the OCSs. Even though rainfall intensity versus rainfall duration revealed a distinct convective and stratiform part, the intensities were lower and the rains in the UOV network seemed to last longer. This indicates a less-vigorous mesoscale circulation and organization. Yet MCSs are organized, and a distinction between "OCSs of the Sudano-Guinean type" for them and "OCSs of the Sahelian type" for the OCS cases would seem to be more appropriate. The latter will prevail at the beginning and end of the rainy season and often be equivalent to a squall-line system.

A third distinct class of rainfall events occurred in a peculiar synoptic situation during which a cyclonic vortex led to deep westerly flow in the UOV region. The so-called vortex-type rainfalls (type III) contributed about $9 \%$ to the annual rainfall totals. These events not only occurred within the peak of the monsoon season in late July and early August, but also in early October. During these periods, the lower and midtroposphere was barotropic; that is, the vertical wind shear and the 
AEJ were lacking. The low CAPE and high LFC values found herein suggested that vertical motion was enhanced due to upper-level divergence within a strong TEJ and/or low-level convergence in the monsoon flow. Taking into account the long duration of the vortextype rainfalls, as well as the fact that they seem to be dynamically rather than thermodynamically caused, it is suggested that they might be similar to "monsoon rains" mentioned by other authors (e.g., Hamilton and Archbold 1945; Omotosho 1985; Kamara 1986; Acheampong 1982; Buckle 1996). However, the present results suggest that it is not a deepening of the monsoon layer that causes the deep westerly flow, but a temporal swing of the easterlies in the middle troposphere due to a quasi-stationary, often-closed cyclonic vortex to the north. Clearly, the definition of "monsoon rains," their contribution to the annual rainfall near the Guinea coast, and their related synoptic evolution dynamics warrant further study. Finally, it is worth mentioning that the seasonal and spatial statistics of rainfall types over West Africa may also impact on the upper-level circulation response to the heating via a potentially varying fraction of stratiform rain related to them. Schumacher and Houze (2003) stress that the monsoon regions, including West Africa, show the largest seasonal variations in stratiform rain fraction.

The results presented offer considerable support for the broader importance of the rainfall classification scheme that was devised and used in this study, for the West African Sudan zone. The local MCS and OCS subtypes IIa and IIb are, however, related to the local climatology of the UOV environment. Moreover, several aspects of this paper need to be further explored. Two subtype Ia and one subtype IIIb cases are described in detail in Schrage et al. (2006). Moreover, enhanced surface and upper-air data that emerge from the AMMA 2006 field campaign will present a unique opportunity to substantiate and explain the relationship between the developing southerly AEW vortices and moist convection, as well as the distinction between the Sahelian-type and Sudano-Guinean-type OCSs in this data-sparse region of West Africa. Another avenue of imminent research could be the investigation of the vortex-type rainfall that should benefit from new radiosonde stations in the moist southern zone.

Acknowledgments. This research is funded by the Federal German Ministry of Education and Research (BMBF) under Grant 01 LW 0301A and by the Ministry of Science and Research (MWF) of the federal state of North Rhine-Westphalia under Grant 223-21200200. The two grants support the IMPETUS project. We thank Ms. Dagmar Janzen for typing parts of the manu- script. We are also grateful to Jon Schrage and Michael Christoph for critically reviewing the manuscript. We are thankful to Christian Depraetere and Jean-Michel Bouchez from the "Institute de Recherche pour le Development" for providing us with the rainfall data. Ernest Afisimama from the Nigerian Meteorological agency kindly furnished the monthly rainfall data from 12 Nigerian synoptic stations. A special thanks is devoted to all members of the IMPETUS radiosonde team, namely, Michael Christoph, Andreas Weimer, and Elisabeth van den Akker. Without their engagement the successful campaign would not have been possible. Finally, the authors thank Dr. Leiterer from the Meteorological Observatory (DWD) in Lindenberg for the lending of his "cloud box" to train the radiosonde in a 100\% RH atmosphere. Dr. Leiterer and his team also trained A. Weimer with regard to the preparation of the sondes for launch. We thank Peter Lamb and an anonymous reviewer for their comments that helped to greatly improve the manuscript.

\section{REFERENCES}

Acheampong, P. K., 1982: Rainfall anomaly along the coast of Ghana-Its nature and causes. Geogr. Ann., 64, 199-211.

Arnaud, Y., M. Desbois, and J. Maizi, 1992: Automatic tracking and characterization of African convective systems on Meteosat pictures. J. Appl. Meteor., 31, 443-453.

Aspliden, C. I., Y. Tourre, and J. B. Sabine, 1976: Some climatological aspects of West African disturbance lines during GATE. Mon. Wea. Rev., 104, 1029-1035.

Barnes, G. M., and K. Sieckman, 1984: The environment of fastand slow-moving tropical mesoscale convective cloud lines. Mon. Wea. Rev., 112, 1782-1794.

Berry, G. J., and C. D. Thorncroft, 2005: Case study of an intense African Easterly Wave. Mon. Wea. Rev., 133, 752-766.

Buckle, C., 1996: Weather and Climate in Africa. Longman, $312 \mathrm{pp}$.

Burpee, R. W., 1974: Characteristics of North African easterly waves during the summers of 1968 and 1969. J. Atmos. Sci, 31, 1556-1570.

Carlson, T. N., 1969a: Synoptic histories of three African disturbances that developed into Atlantic hurricanes. Mon. Wea. Rev., 97, 256-276.

— 1969b: Some remarks on African disturbances and their progress over the tropical Atlantic. Mon. Wea. Rev., 97, 716726.

Chong, M., and D. Hauser, 1989: A tropical squall line observed during the COPT 81 experiment in West Africa. Part II: Water budget. Mon. Wea. Rev., 117, 728-744.

__, P. Amayenc, G. Scialom, and J. Testud, 1987: A tropical squall line observed during the COPT 81 experiment in West Africa. Part I: Kinematic structure inferred from dualDoppler radar data. Mon. Wea. Rev., 115, 670-694. 
Desbois, M., T. Kayiranga, B. Gnamien, S. Guessous, and L. Picon, 1988: Characterization of some elements of the Sahelian climate and their interannual variations for July 1983, 1984 and 1985 from the analysis of Meteosat ISCCP data. J. Climate, 1, 867-904.

Dhonneur, G., 1981: Les amas nuageux mobiles principale composante de la météorologie du Sahel. La Météorologie, 27, $75-82$.

Diedhiou, A., S. Janicot, A. Viltard, P. de Felice, and H. Laurent, 1999: Easterly wave regimes and associated convection over West Africa and tropical Atlantic: Results from the NCEP/ NCAR and ECMWF reanalyses. Climate Dyn., 15, 795-822.

Duvel, J. P., 1989: Convection over tropical Africa, and the Atlantic Ocean during northern summer. Part I: Interannual and diurnal variations. Mon. Wea. Rev., 117, 2782-2799.

- 1990: Convection over tropical Africa and the Atlantic Ocean during northern summer. Part II: Modulation by easterly waves. Mon. Wea. Rev., 118, 1855-1868.

Eldridge, R. H., 1957: A synoptic study of West African disturbance lines. Quart. J. Roy. Meteor. Soc., 83, 303-314.

Ermert, V., 2004: Typisierung von Niederschlagsereignissen in der westafrikanischen Sudanzone während des Sommermonsuns 2002. M.S. thesis, Institute of Geophysics und Meteorology, University of Cologne, 103 pp. [Available online at http:// www.meteo.uni-koeln.de/content/downloads/literatur/ ermertdiplom.pdf.]

Fink, A. H., and P. Knippertz, 2003: An extreme precipitation event in southern Morocco in spring 2002 and some hydrological implication. Weather, 58, 377-388.

— tion between African easterly waves and West African squall lines in 1998 and 1999. J. Geophys. Res., 108, 4332, doi:10.1029/2002JD002816.

— , D. G. Vincent, P. M. Reiner, and P. Speth, 2004: Mean state and wave disturbances during phases I, II, and III of GATE based on ERA-40. Mon. Wea. Rev., 132, 1661-1683.

Fortune, M., 1980: Properties of African squall lines from timelapse satellite imagery. Mon. Wea. Rev., 108, 153-168.

Greenfield, R. S., and J. S. Fein, 1979: The global atmospheric research program's Atlantic Ocean tropical experiment. Rev. Geophys. Space Phys., 17, 1762-1772.

Hamilton, R. A., and J. W. Archbold, 1945: Meteorology of Nigeria and adjacent territories. Quart. J. Roy. Meteor. Soc., 71, 231-265.

Hodges, K. I., and C. D. Thorncroft, 1997: Distribution and statistics of African mesoscale convective weather systems based on the ISCCP Meteosat imagery. Mon. Wea. Rev., 125, 2821-2837.

Houze, R. A., Jr., and A. K. Betts, 1981: Convection in GATE. Rev. Geophys. Space Phys., 19, 541-576.

Kamara, I., 1986: The origins and types of rainfall in West Africa. Weather, 41, 48-56.

Knippertz, P., A. H. Fink, A. Reiner, and P. Speth, 2003: Three late summer/early autumn cases of tropical-extratropical interactions causing precipitation in northwestern Africa. Mon. Wea. Rev., 131, 116-135.

Laing, A. G., J. M. Fritsch, and A. J. Negri, 1999: Contribution of mesoscale convective complexes to rainfall in Sahelian Africa: Estimates from geostationary infrared and passive microwave data. J. Appl. Meteor., 38, 957-964.

Landsea, C. W., and W. M. Gray, 1992: The strong association between western Sahelian monsoon rainfall and intense Atlantic hurricanes. J. Climate, 5, 435-453.
Le Barbé, L., and T. Lebel, 1997: Rainfall climatology of the HAPEX-Sahel region during the years 1950-1990. J. Hydrol., 188-189, 43-73.

— - _ and D. Tapsoba, 2002: Rainfall variability in West Africa during the years 1950-90. J. Climate, 15, 187-202.

Mathon, V., and H. Laurent, 2001: Life cycle of Sahelian mesoscale convective cloud systems. Quart. J. Roy. Meteor. Soc., 127, 377-406.

_ - A. Diedhiou, and H. Laurent, 2002a: Relationship between easterly waves and mesoscale convective systems over the Sahel. Geophys. Res. Lett., 29, 1216, doi:10.1029/ 2001GL014371.

- H. Laurent, and T. Lebel, 2002b: Mesoscale convective system rainfall in the Sahel. J. Appl. Meteor., 41, 1081-1092.

McGarry, M. M., and R. J. Reed, 1978: Diurnal variations in convective activity and precipitation during phases II and III of GATE. Mon. Wea. Rev., 106, 101-113.

Nesbitt, S. W., and E. J. Zipser, 2003: The diurnal cycle of rainfall and convective intensity according to three years of TRMM measurements. J. Climate, 16, 1456-1475.

Omotosho, J. B., 1984: Spatial and seasonal variation of line squalls over West Africa. Arch. Meteor. Geophys. Bioclimatol., 33, 143-150.

- 1985: The separate contribution of line squalls, thunderstorms and the monsoon to the total rainfall in Nigeria. $J$. Climatol., 5, 543-552.

Payne, S. W., and M. M. McGarry, 1977: The relationship of satellite inferred convective activity to easterly waves over West Africa and the adjacent ocean during phase III of GATE. Mon. Wea. Rev., 105, 413-420.

Peters, M., and G. Tetzlaff, 1988: The structure of West African squall lines and their environmental moisture budget. Meteor. Atmos. Phys., 39, 74-84.

$\longrightarrow,-$, and W. Janssen, 1989: Rainfall intensity of West African squall lines. Ann. Geophys., 7, 227-238.

Redelsperger, J.-L., A. Diongue, A. Diedhiou, J.-P. Ceron, M. Diop, J.-F. Gueremy, and J.-P. Lafore, 2002: Multi-scale description of a Sahelian synoptic weather system representative of the West African monsoon. Quart. J. Roy. Meteor. Soc., 128, 1229-1257.

Reed, R. J., D. C. Norquist, and E. E. Recker, 1977: The structure and properties of African wave disturbances as observed during phase III of GATE. Mon. Wea. Rev., 105, 317-333.

Roux, F., 1988: The West African squall line observed on 23 June 1981 during COPT 81: Kinematics and thermodynamics of the convective region. J. Atmos. Sci., 45, 406-426.

—_ J. Testud, M. Payen, and B. Pinty, 1984: West African squall-line thermodynamic structure retrieved from dualDoppler radar observations. J. Atmos. Sci., 41, 3104-3121.

Rowell, D. P., and J. R. Milford, 1993: On the generation of African squall lines. J. Climate, 6, 1181-1193.

Schrage, J. M., A. H. Fink, V. Ermert, and E. D. Ahlonson, 2006: Three MCS cases occurring in different synoptic environments in the sub-Sahelian wet zone during the 2002 West African monsoon. J. Atmos. Sci., in press.

Schumacher, C., and R. A. Houze Jr., 2003: The TRMM precipitation radar's view of shallow, isolated rain. J. Appl. Meteor., 42, 1519-1524.

Shinoda, M., T. Okatani, and M. Saloum, 1999: Diurnal variations of rainfall over Niger in the West African Sahel: A comparison between wet and drought years. Int. J. Climatol., 19, 8194.

Sommeria, G., and J. Testud, 1984: COPT 81: A field experiment 
designed for the study of dynamics and electrical activity of deep convection in continental tropical regions. Bull. Amer. Meteor. Soc., 65, 4-10.

Taylor, M., D. J. Parker, C. R. Lloyd, and C. D. Thorncroft, 2005: Observations of synoptic scale land surface variability and its coupling with the atmosphere. Quart. J. Roy. Meteor. Soc., 131, 913-938.

Tetzlaff, G., and M. Peters, 1988: A composite study of early summer squall lines and their environment over West Africa. Meteor. Atmos. Phys., 38, 153-163.

Thorncroft, C. D., and Coauthors, 2003: The JET2000 project-
Aircraft observations of the African easterly jet and African easterly waves. Bull. Amer. Meteor. Soc., 84, 337-351.

Vollmert, P., A. H. Fink, and H. Besler, 2003: "Ghana Dry Zone" und "Dahomey Gap": Ursachen für eine Niederschlagsanomalie im tropischen Westafrika. Erde, 134, 375-393.

Waple, A. M., and J. H. Lawrimore, 2003: State of the climate in 2002. Bull. Amer. Meteor. Soc., 84, S1-S68.

Zipser, E. J., 1977: Mesoscale and convective-scale downdrafts as distinct components of squall-line structure. Mon. Wea. Rev., 105, 1568-1589. 